\title{
Initiation of Mauthner- or Non-Mauthner-Mediated Fast Escape Evoked by Different Modes of Sensory Input
}

\author{
Tsunehiko Kohashi ${ }^{1,2}$ and Yoichi Oda ${ }^{1}$ \\ ${ }^{1}$ Division of Biological Science, Graduate School of Science, Nagoya University, Nagoya 464-8602, Japan, and 2Neuroscience Laboratories, Graduate School \\ of Frontier Biosciences, Osaka University, Suita, Osaka 565-0871, Japan
}

\begin{abstract}
Brainstem reticulospinal neurons (RSNs) serve as the major descending system in vertebrate sensorimotor integration. One of the paired RSNs in zebrafish, the Mauthner (M) cell, is thought to initiate fast escape from sudden noxious stimuli. Two other paired RSNs, morphologically homologous to the M-cell, are also suggested to play key roles in controlling fast escape. However, the relationship among activities of the M-cell and its homologs during fast escape and the sensory inputs that elicit escape via their activation are unclear. We have monitored hindbrain RSN activity simultaneously with tail flip movement during fast escape in zebrafish. Confocal calcium imaging of RSNs was performed on larvae rostrally embedded in agar but with their tails allowed to move freely. Application of a pulsed waterjet to the otic vesicle $(\mathrm{OV})$ to activate acousticovestibular input elicited contralateral fast tail flips with short latency and an apparent $\mathrm{Ca}^{2+}$ increase, reflecting a single action potential, in the ipsilateral M-cell (M-escape). Application of waterjet to head skin for tactile stimulation elicited fast escapes, but onset was delayed and the M-cell did not fire (non-M-escape). After eliminating either the M-cell or $\mathrm{OV}$, only non-M-escape was initiated. Simultaneous high-speed confocal imaging of the M-cell and one of its homologs, MiD3cm, revealed complementary activation during fast escape: $\mathrm{MiD} 3 \mathrm{~cm}$ activity was low during $\mathrm{M}$-escape but high during non-M-escape. These results suggest that M-cell firing is necessary for fast escape with short latency elicited by acousticovestibular input and that MiD3cm is more involved in non-M-escape driven by head-tactile input.
\end{abstract}

Key words: Mauthner cell; calcium imaging; zebrafish; escape; reticulospinal neurons; hindbrain

\section{Introduction}

Brainstem reticulospinal neurons (RSNs) are phylogenetically conserved across vertebrates (Nieuwenhuys et al., 1998) and form a major descending motor control system that receives convergent sensory inputs and sends motor commands to spinal circuitry (Rossignol et al., 2006; Grillner et al., 2008). Subpopulations of RSNs located in discrete brainstem regions are recruited in the control of different components of sensorimotor integration (Dampney, 1994; Ullén et al., 1997; Orlovsky et al., 1999; Fagerstedt et al., 2001; Yeomans et al., 2002; Dubuc et al., 2008). In teleost fish, lesion experiments and imaging of neuronal activity suggest that subpopulations of RSNs in midbrain and hindbrain are important for control of visual prey capture (Gahtan et al., 2005), fast escape (see below), and optomotor response (Orger et al., 2008).

Particularly in zebrafish and goldfish, three bilateral pairs of identified RSNs repeated in the middorsal region of adjacent hindbrain segments (fourth to sixth), the Mauthner (M) cell, $\mathrm{MiD} 2 \mathrm{~cm}$, and $\mathrm{MiD} 3 \mathrm{~cm}$ [collectively called the M-series (Lee and

Received April 4, 2008; revised Aug. 6, 2008; accepted Sept. 4, 2008.

This work was supported by Grants-in-Aid for Scientific Research (KAKENHI) from the Ministry of Education, Culture, Sports, Science, and Technology of Japan (12053246, 17023029), and the Japan Society for the Promotion of Science (18300134) (Y.0.). We thank Drs. S. Takagi, H. Hirata, and E. S. Ruthazer for helpful comments.

Correspondence should be addressed to Yoichi Oda, Division of Biological Science, Graduate School of Science, Nagoya University, Furo, Chikusa, Nagoya 464-8602, Japan. E-mail: oda@bio.nagoya-u.ac.jp.

DOI:10.1523/JNEUROSCI.1435-08.2008

Copyright $\odot 2008$ Society for Neuroscience ～0270-6474/08/2810641-13\$15.00/0
Eaton, 1991)], are proposed to be involved in initiation and control of fast escape from aversive sound, vibratory, tactile, or visual stimuli (Foreman and Eaton, 1993; Liu and Fetcho, 1999; Weiss et al., 2006). The morphologically similar M-series neurons are referred to as the segmental homologs (Metcalfe et al., 1986) and are indicated to act as a functional unit in escape behavior (O'Malley et al., 1996; Liu and Fetcho, 1999; Nakayama and Oda, 2004).

Spiking of the M-cell is thought to initiate fast escape with $\mathrm{C}$-shaped body bending because it has been shown in goldfish that onset of C-shaped bending is tightly correlated with the preceding extracellular field potential of M-cell spiking (Zottoli, 1977; Eaton et al., 1981, 1988; Weiss et al., 2006) and that an M-cell action potential activates contralateral trunk muscle to bend the body (for review, see Fetcho, 1991). However, a similar fast escape still occurs after M-cell ablation (Eaton et al., 1982; DiDomenico et al., 1988; Liu and Fetcho, 1999; Zottoli et al., 1999), leading to the proposal that there is another pathway for fast escape that is not initiated by $\mathrm{M}$-cell firing (non-M-escape) (Eaton et al., 1984). Lesioning of all the M-series neurons abolished the fast escape with short latency (Liu and Fetcho, 1999), indicating that the $\mathrm{M}$-cell homologs are involved in the non-Mescape pathway.

However, the functional relationship among the M-series neurons and how sensory inputs are processed into an escape command through the $\mathrm{M}$-series remain unclear because RSN activity has not yet been observed directly during escape. In the present study, we performed in vivo confocal $\mathrm{Ca}^{2+}$ imaging of 
RSNs (O’Malley et al., 1996; Gahtan et al., 2002), simultaneously monitoring the escape in partially restrained larval zebrafish (Ritter et al., 2001; Bhatt et al., 2007). Our results suggest that there are duplicate pathways involving either the M-cell or its segmental homolog, MiD3 $\mathrm{cm}$, for initiating fast escape in zebrafish: the M-cell pathway is preferentially activated by auditory or vibratory stimulus, whereas the $\mathrm{MiD} 3 \mathrm{~cm}$ pathway is triggered by headtactile stimulus.

\section{Materials and Methods}

Animals. Experiments were performed on 5-9 d postfertilization (dpf) larval zebrafish (Danio rerio) at room temperature $\left(27-29^{\circ} \mathrm{C}\right)$. Larvae were obtained from an adult zebrafish colony and raised at $28.5^{\circ} \mathrm{C}$. By this stage, larvae start swimming, feeding, and showing escape in response to tactile and vibratory stimulation (Budick and O'Malley, 2000; Burgess and Granato, 2007). All procedures were performed in compliance with the guidelines approved by the Animal Care and Use Committee of Nagoya University and stipulated by the Osaka University Committee on Animal Research.

Retrograde labeling of $M$-series neurons. Hindbrain RSNs were labeled with a fluorescent $\mathrm{Ca}^{2+}$ indicator Oregon Green BAPTA-1 dextran (OGB1) (10,000 molecular weight; Invitrogen) as follows. Larvae were anesthetized with $0.01 \% 3$-aminobenzoic acid ethyl ester (MS222) (Sigma-Aldrich) in 10\% HBSS (in mм: $13.7 \mathrm{NaCl}, 0.54 \mathrm{KCl}, 0.025 \mathrm{Na}_{2} \mathrm{HPO}_{4}$, $0.044 \mathrm{KH}_{2} \mathrm{PO}_{4}, 0.13 \mathrm{CaCl}_{2}, 0.10 \mathrm{MgSO}_{4}$, and $0.42 \mathrm{NaHCO}_{3}, \mathrm{pH} 7.2$ ) chilled on ice. To label M-series neurons retrogradely, a 33\% solution of OGB1 in $10 \%$ HBSS was pressure-injected via a glass microcapillary (tip diameter, $\sim 10$ $\mu \mathrm{m}$ ) into the caudal spinal cord (at approximately the level of the 22nd myotome) using a Picospritzer III (Parker Hannifin). A small injection did not disturb the movement of the body rostral to the injection site. After the injection, larvae were allowed to recover in $10 \%$ HBSS $\left(28.5^{\circ} \mathrm{C}\right)$ for $>9 \mathrm{~h}$.

Semifixed preparation. For simultaneous monitoring of RSN activity and behavioral response, the larvae were placed in an agar-coated glass recording chamber. The rostral one-half of the body was embedded in $3.5 \%$ agar (low-melting point agarose, gelled at $28^{\circ} \mathrm{C}$; Invitrogen) with its dorsal side up [modified from the study by Ritter et al. (2001)]. The chamber was filled with $10 \%$ HBSS after the agar had congealed. For application of water pulse stimuli to the head, the agar covering the otic vesicle $(\mathrm{OV})$ or head skin rostral to the $\mathrm{OV}$ was cut out on one side. For monitoring tail movements, the tail caudal to the cloaca and well anterior to the OGB1-injected site was exposed (see Fig. $1 B$ ). During all experiments, the viability of the fish was carefully monitored by observing the fast blood flow in thin vessels within the brain.

Behavioral analysis of fast escape. Escape responses were elicited by a water pulse applied every $5 \mathrm{~min}$ to the OV or rostral head skin through a syringe needle (26 gauge; inner diameter, $220 \mu \mathrm{m}$; Terumo). In some experiments, the water pulse was applied to one side of the tail at level of the cloaca. The water pulses were generated by a pressure pulse of $3 \mathrm{~ms}$ duration delivered from a Picospritzer. The pressure was normally adjusted to $<30 \mathrm{psi}$, unless otherwise noted. When the semifixed larva was
Unrestrained

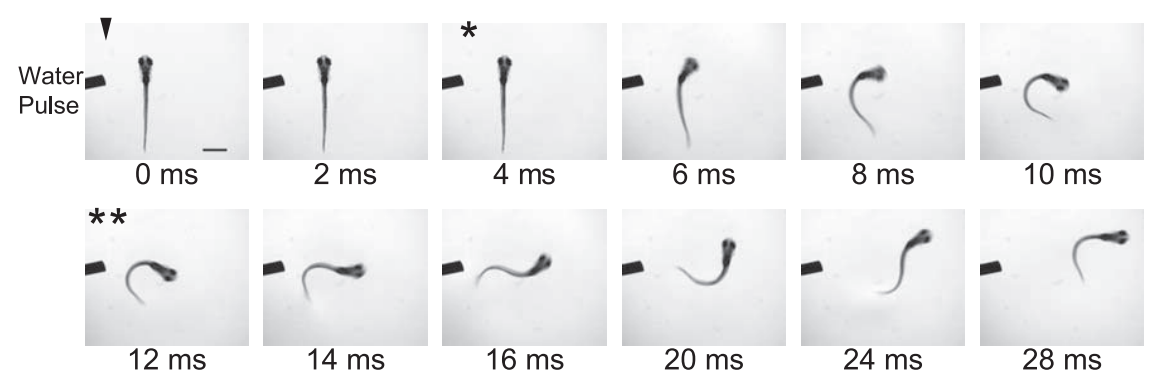

B2 Semi-fixed
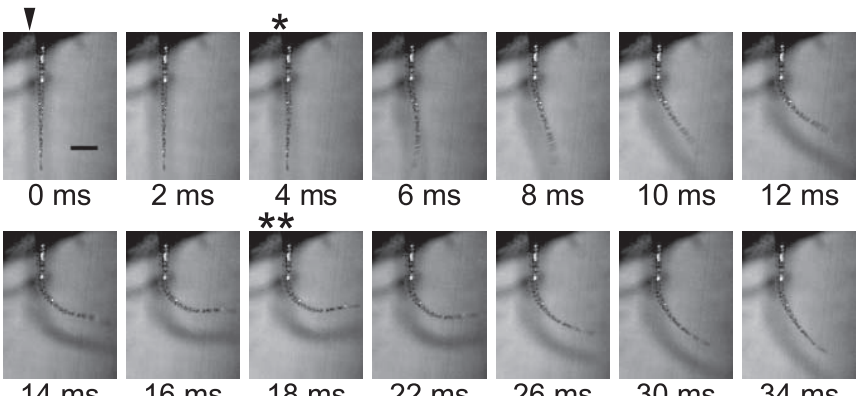

$14 \mathrm{~ms}$

$16 \mathrm{~ms}$

$18 \mathrm{~ms}$
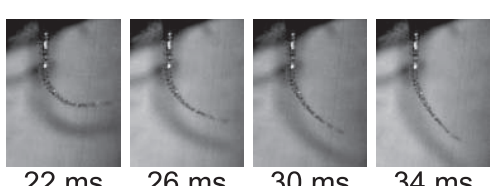

$\mathrm{C} 2$

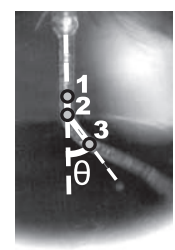

C3

Tail Flexion Angle

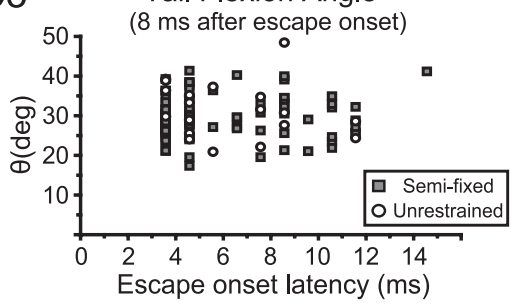

Figure 1. Comparison of the tail movements of unrestrained and partially restrained zebrafish larvae. $A$, The fast escape of unrestrained fish elicited by a water pulse applied to head. The initial strong bend along the whole length of the body, away from the stimulus, and the following counter bend represent the typical features of the fast escape of teleosts. The time from the wate Tail flip response of the partially restrained (semifixed) Iarva. $\boldsymbol{B} 1$, The rostral body, anterior to the cloaca, of the larval zebrafish was (ordinate) are plotted against escape onset latency (abscissa). Data of the semifixed tail flips (squares) are in the same range as those of unrestrained fast escapes (circles).

stimulated, the needle tip was kept $0.5 \mathrm{~mm}$ apart from the surface of the fish with a micromanipulator (MM-200; Narishige). To observe escape in the unrestrained preparations, the larvae were placed in a Petri dish $(3.5 \mathrm{~cm})$ filled with $10 \%$ HBSS at a depth of 3-4 mm and the tip of the water stimulus needle was positioned $1-3 \mathrm{~mm}$ from the fish.

Sequential images of the escape response were captured with a highspeed digital camera (captured every $1 \mathrm{~ms}$; Fastcam Ultima 1024 or Fastcam 1024 PCI; Photoron) and saved with Fastcam Viewer, version 2.4.3.2, software (Photoron). Latency was defined as the time from the arrival of the water pulse to the head of the fish to the beginning of tail movement. The water arrival time in the semifixed preparations, estimated as the time of delivery of the water to $0.5 \mathrm{~mm}$ from the syringe needle in air, was $0.41,0.44$, and $0.65 \mathrm{~ms}$ for stimulus pulses at a pressure of 20,15 , and $10 \mathrm{psi}$, respectively. The estimated time was confirmed by the observation of a slight depression of the otic vesicle in response to a strong water pulse ( $>20 \mathrm{psi})$. In the unrestrained preparations, the water arrival time was visually determined as the time it took the ripple of water stimulus to reach the head of the fish.

Tail flexion responses with latency shorter than $15 \mathrm{~ms}$ were analyzed 


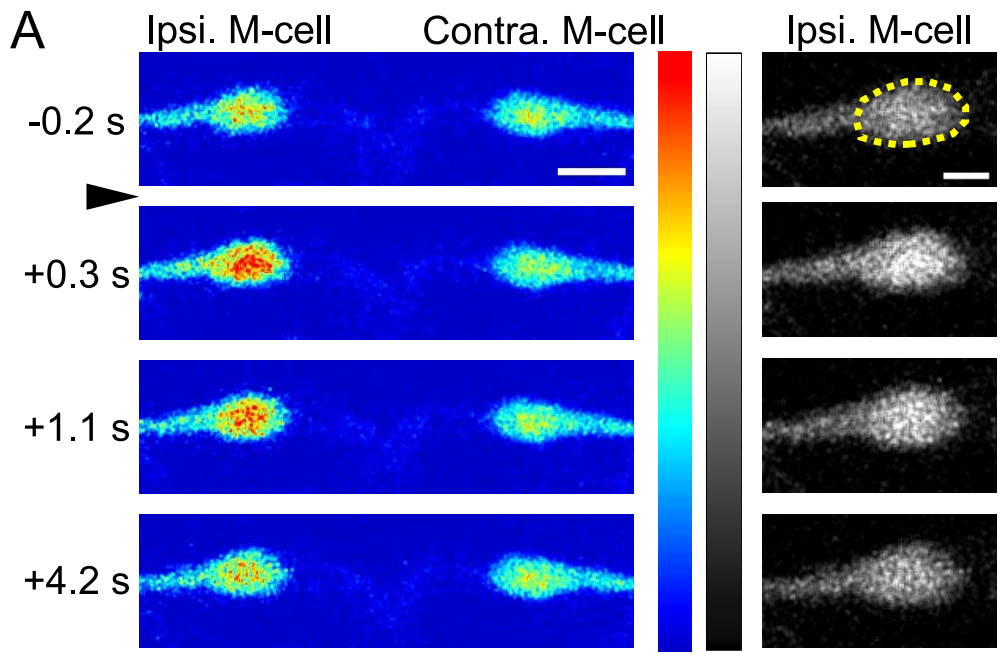

B1

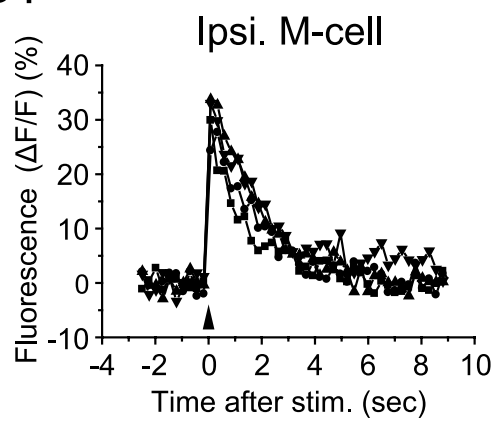

C1

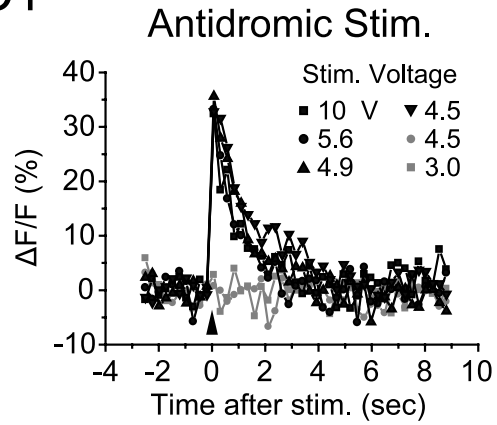

B2

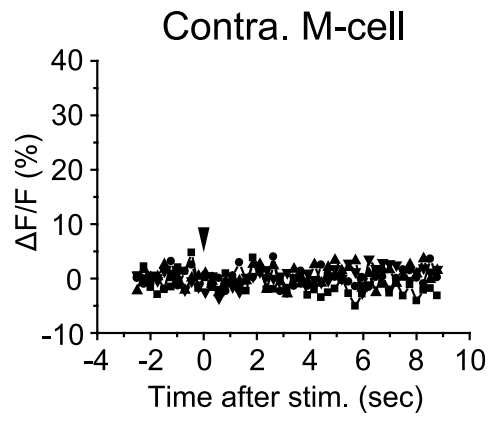

C2

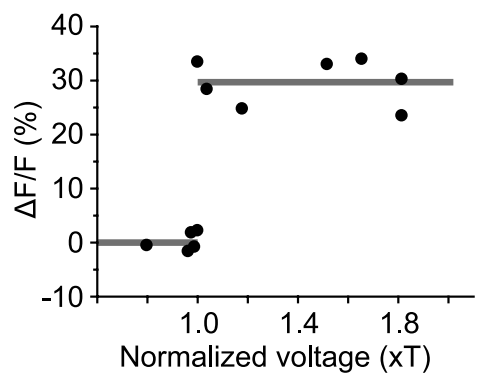

Figure 2. Fluorescence response of the paired M-cells associated with fast escape. $A$, Typical fluorescence responses of the paired M-cells, obtained simultaneously with the tail response of Figure 1B2. Left, Pseudocolored images of the fluorescence responses before $(-0.2 s)$ and after $(+0.3,1.1$, and $4.2 \mathrm{~s})$ the water pulse arrival (arrowhead). The M-cell ipsilateral to the stimulus (Ipsi. M-cell; gray scale images are shown on right) showed an apparent increase in fluorescence, whereas the contralateral M-cell (Contra. M-cell) did not. Scale bars: left, $20 \mu \mathrm{m}$; right, $10 \mu \mathrm{m}$. The color and gray scales represent fluorescence intensity (blue or black, lowest; red or white, highest). $\boldsymbol{B}$, Fractional changes in fluorescence ( $\Delta F / F$; ordinate) in the somata of the $M$-cells (the area in the dashed yellow line in $A$ ) accompanied with fast escape (escape onset latencies, 3-5 ms) were plotted against the time after stimulus arrival (abscissa). The responses of four trials obtained from the pair shown in $A$ are superimposed (data exemplified in $A$ are shown as triangles). The ipsilateral $M$-cell exhibited large transient increases in fluorescence (B1; peak $\Delta F / F, 25-35 \%)$, whereas the contralateral $\mathrm{M}$-cell did not show any apparent fluorescence response (B2). C1, Fluorescence responses associated with an antidromic spike of the same ipsilateral M-cell in response to electrical stimulation applied to the spinal cord, which appeared in an all-or-nothing manner with different stimulus intensity (volts) as denoted. The amplitude of suprathreshold fluorescence responses is comparable with that of the large sensory-evoked responses in $\mathbf{B 1}$. $\mathbf{C 2}$, The amplitude of the fluorescence response (ordinate) associated with the AD spike of another M-cell is plotted against the intensities of spinal cord stimulation (abscissa; normalized by the threshold voltage, $T$ ). The constant increase in fluorescence at the suprathreshold stimulus (average amplitude, 29.6\%; right gray line) is consistent with the generation of a single antidromic spike (Takahashi et al., 2002). The left gray line indicates $0 \%$.

(see Results and Discussion). The tail flexion angle $(\theta)$ was measured from the three dots on the midline as shown in Figure 1,C1 and C2. The dots were positioned at the cloaca (dot 2), L/12 rostral (dot 1) and $L / 6$ caudal ( $\operatorname{dot} 3$ ) to $\operatorname{dot} 2 ; L$ represents the distance from the caudal end of the swim bladder to the tip of the tail. All the dots were rostral to the OGB1 injection site. Assignment of the dots and measurement of the flexion angle were performed with motion analysis software (Dipp-Motion 2D; Ditect). The angular velocity was calculated from flexion angles smoothed with a three-point moving average filter.

Optics for simultaneous monitoring of $M$-series activity and behavior. Calcium imaging of the M-series neurons was performed with an upright microscope (BX51WI; Olympus) with a water-immersion objective [LUMPlanFL 40×W/IR; 40×; numerical aperture (NA), 0.8; Olympus]. The inverted optics for behavioral recording was attached below a manipulation stage and consisted of a low-magnification objective (XLFluor $2 \times 1340 ; 2 \times$; NA, 0.14; Olympus), a dual port (U-DP; Olympus) with an imaging lens unit (U-DP1xC; Olympus) and a high-speed digital camera (Fastcam Ultima 1024 or Fastcam 1024 PCI). The tail of the semifixed preparation was illuminated with orange light (wavelengths, 590-670 nm) that did not interfere with confocal imaging. The manipulation stage was completely isolated from both of the optics. The axes of the two optical systems could be moved independently to focus on neurons and the tail.

Calcium imaging with confocal microscopy. $\mathrm{M}$-series neurons were illuminated with a 488 $\mathrm{nm}$ argon laser line and the fluorescence images of them were captured with a conventional confocal scanner (FV300; Olympus; emission filter, 510-530 nm), or a high-speed, Nipkow disk confocal scanner (CSU10; Yokogawa; emission filter, $510-550 \mathrm{~nm}$ ) with a high-sensitivity digital camera (EM-CCD Camera C9100-12; Hamamatsu Photonics) mounted on the upright optics. Before each trial, a series of horizontal optical sections spanning the cells was collected and the brightest plane of each cell to image was determined, which ensured that the increase in fluorescence of the cell was not a result of its movement into a brighter plane (O’Malley et al., 1996).

Images $(512 \times 512$ pixels $)$ recorded with the FV300 confocal system were collected every 260 $\mathrm{ms}$. In some cases, the fluorescence response of $\mathrm{MiD} 2 \mathrm{~cm}$ or $\mathrm{MiD} 3 \mathrm{~cm}$ was recorded with higher magnification to enhance the signal-to-noise ratio of the fluorescence intensity of cell body. We used Fluoview ver.3.3 software (Olympus) for operation of the confocal scanner and image acquisition.

In experiments using the CSU10 system, a piezoelectric high-speed focusing device (PIFOC P-721LLQ, operated with an E-662 amplifier and servo-controller; Physik Instrumente) mounted on the objective lens was used to switch the focal plane in synchronization with the collection of fluorescence images. Typically, we imaged $(512 \times 512$ pixels $)$ two focal planes alternately at $130 \mathrm{~ms}$ intervals (see Fig. 9A). We used MetaMorph 6.1 software (Molecular Devices) to synchronize the CSU-10 shutter, camera shutter, and focus switching.

After $\mathrm{Ca}^{2+}$ imaging of the M-series neurons during escape, fluorescence responses associated with antidromic $(\mathrm{AD})$ action potentials of the 
same neurons were examined. The larvae were anesthetized with $0.01 \%$ MS222, reembedded in $3.5 \%$ agar, and immobilized with injection of D-tubocurarine chloride solution $(3 \mathrm{mg} / \mathrm{ml}$; Sigma-Aldrich) to prevent tail movement evoked by $\mathrm{AD}$ stimulation from injury to the spinal cord. To stimulate the axons of the M-series (Furshpan and Furukawa, 1962; Eaton and Farley, 1975; Takahashi et al., 2002; Nakayama and Oda, 2004), a bipolar tungsten electrode was placed on the spinal cord rostral to the OGB1-injected site through a small hole cut in the agar and bipolar pulsed currents were delivered (pulse duration, $80 \mu \mathrm{s}$ ).

Quantification of fluorescence response. Before the quantification of fluorescence, background correction was done on the raw fluorescence images. Fluorescence intensities of the cell bodies were measured and the relative changes in fluorescence from the resting intensity $(\Delta F / F)$ were calculated. The first frame after stimulation was excluded from the analysis because it was affected by the movement of the larva. For the M-cell, the second frame after stimulation was used to measure the amplitude of the response. For MiD2 $\mathrm{cm}$ and $\mathrm{MiD} 3 \mathrm{~cm}$, the fluorescence intensities obtained from the second to fifth frame after stimulation were averaged to improve the signal-to-noise ratio, because the responses of the two cells were smaller than that of the M-cell.

Laser ablation of $M$-cells. To ablate M-cells, an FV300 system with a $60 \times$ water objective (LUMPLanFL60x; NA, 0.9; Olympus) was used, and the laser beam was applied to the fluorescence-labeled M-cell of zebrafish embedded in agar, as described previously (Liu and Fetcho, 1999). The argon laser at maximum strength was focused on the middle of the M-cell soma in the point-scanning mode. Exposure for 15 min was usually required to ablate the M-cell. After the exposure, the fish was gently removed from the agar and held in 10\% HBSS for $0.5-1 \mathrm{~d}$ before a postlesion behavioral test. The success of the ablation was verified by observing no recovery of fluorescence at the soma of the M-cell and its truncated axon with the FV300 system on the day after ablation (see Fig. 5A).

Deprivation of sensory input. To eliminate sensory inputs from the OV, the otoliths on one side were ablated by intense laser pulses (see Fig. $6 B$ ) or surgically eliminated with a fine tungsten needle. Larvae were anesthetized in $0.01 \%$ MS222, and then embedded on their side in 3.5\% agar. Laser ablation was performed using a MicroPoint (Photonic Instruments) laser system mounted on a Zeiss Axoplan 2 upright microscope with a $40 \times$ water-immersion objective (Achroplan $\times 40$; NA, 0.75 ; Zeiss). Otoliths were irradiated with a $440 \mathrm{~nm}$ coumarin laser pumped by a UV laser (NL100 nitrogen laser; pulse energy, $175 \mu$ J; Stanford Research Systems). Only a few laser pulses were applied to crack and split an otolith into pieces without any sign of bleeding after ablation. Soon after the fish had recovered from anesthesia, they started swimming but lost balance to keep their dorsal side up and they showed abnormal rotation. The behavioral deficits did not recover on the following days. These observations suggested successful deprivation of inner ear function. The postlesion testing was performed at $1-12 \mathrm{~h}$ after the ablation of otoliths.
A

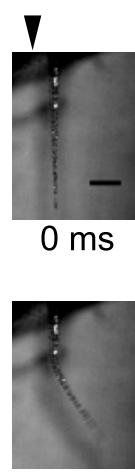

$13 \mathrm{~ms}$

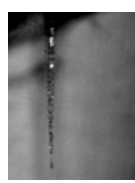

$2 \mathrm{~ms}$

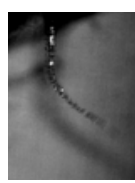

$15 \mathrm{~ms}$

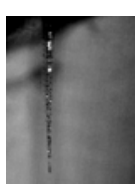

$4 \mathrm{~ms}$

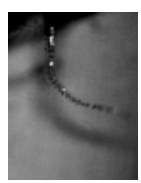

$17 \mathrm{~ms}$

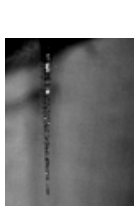

$6 \mathrm{~ms}$

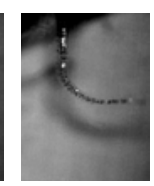

$19 \mathrm{~ms}$

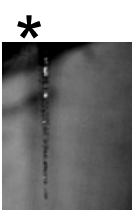

$7 \mathrm{~ms}$ **

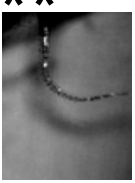

$21 \mathrm{~ms}$

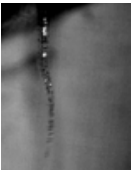

$9 \mathrm{~ms}$

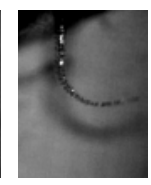

$25 \mathrm{~ms}$

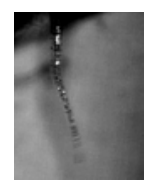

$11 \mathrm{~ms}$

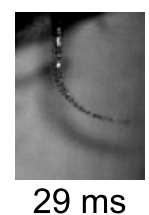

B

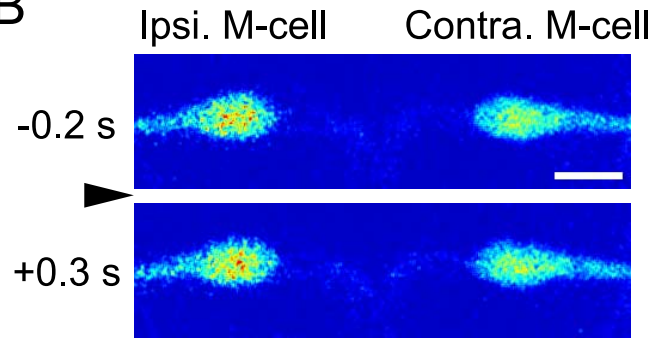

$+1.1 \mathrm{~s}$

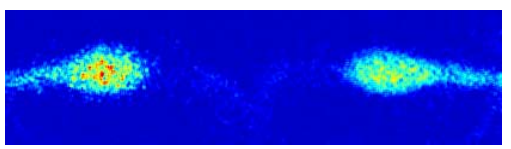

$+4.2 \mathrm{~s}$
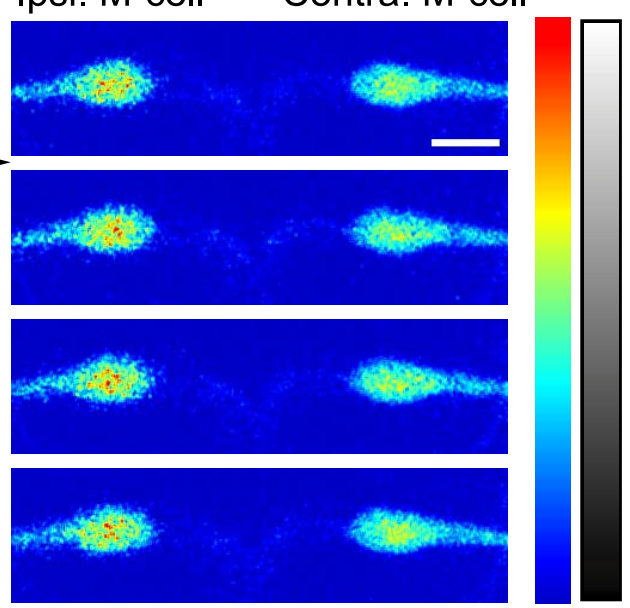

Ipsi. M-cell
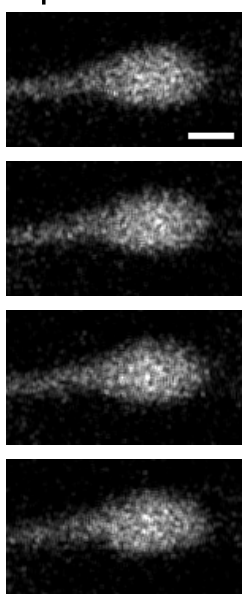

C1

Ipsi. M-cell

$\mathrm{C} 2$
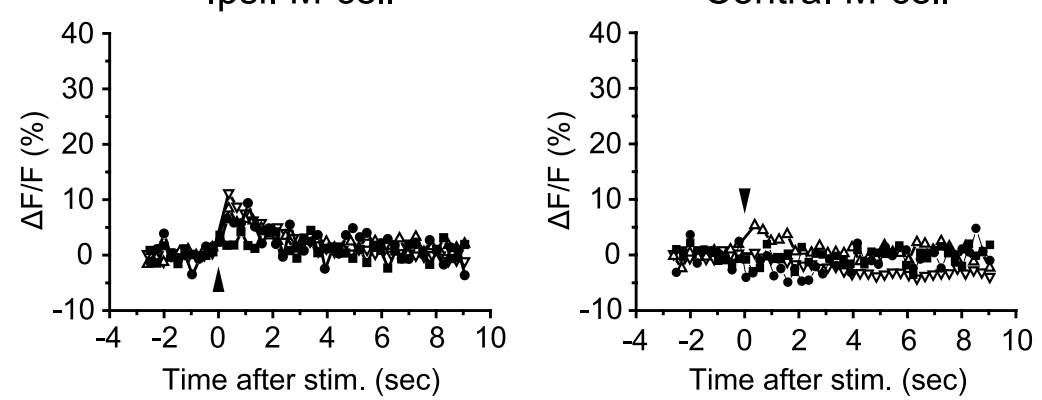

Figure 3. Small fluorescence response of the M-cell associated with the delayed fast escape. $A$, In some cases, onset of the tail flip was delayed in the same animal as shown in Figure $1 B 2$. Note that the time course of the delayed tail flexion after onset is similar to that with short latency. The arrowhead and single and double asterisks are the same as in Figure 1 . Scale bar, $0.5 \mathrm{~mm}$. $\boldsymbol{B}$, Fluorescence images of the paired M-cells taken simultaneously with $\boldsymbol{A}$. Neither of the M-cells shows apparent change in fluorescence (left). Grayscale images of the ipsilateral M-cell are shown on the right. Scale bars: left, $20 \mu \mathrm{m}$; right, $10 \mu \mathrm{m}$. C, Quantification of changes in fluorescence in two pairs of ipsilateral ( $\mathbf{C}$ ) and contralateral ( $\mathbf{C}$ ) M-cells (filled and open symbols for each pair) associated with fast escapes with an onset latency of 7-9 ms. The responses indicated by filled squares are obtained from $\boldsymbol{B}$. In these trials, the M-cells exhibit only a small or no apparent increase in fluorescence.

The lateral line system was blocked by degenerating neuromast hair cells pharmacologically (supplemental Fig. 1, available at www.jneurosci.org as supplemental material). Larvae were immersed in $10 \%$ HBSS containing $300-500 \mu \mathrm{M}$ neomycin sulfate (Wako) and incubated (at $28.5^{\circ} \mathrm{C}$ ) for $1 \mathrm{~h}$ as reported previously (Harris et al., 2003). The fish were then rinsed three times quickly in normal $10 \% \mathrm{HBSS}$ and returned to an incubator at $28.5^{\circ} \mathrm{C}$. The imaging tests were performed during the next $3-9 \mathrm{~h}$ before 


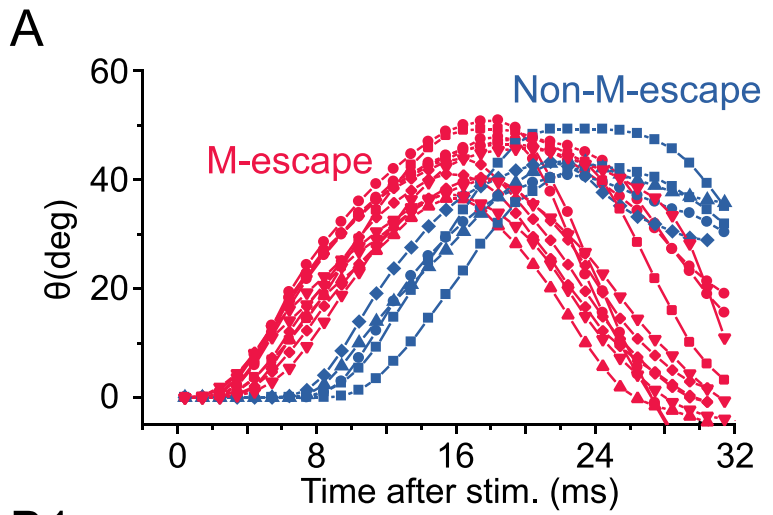

B1
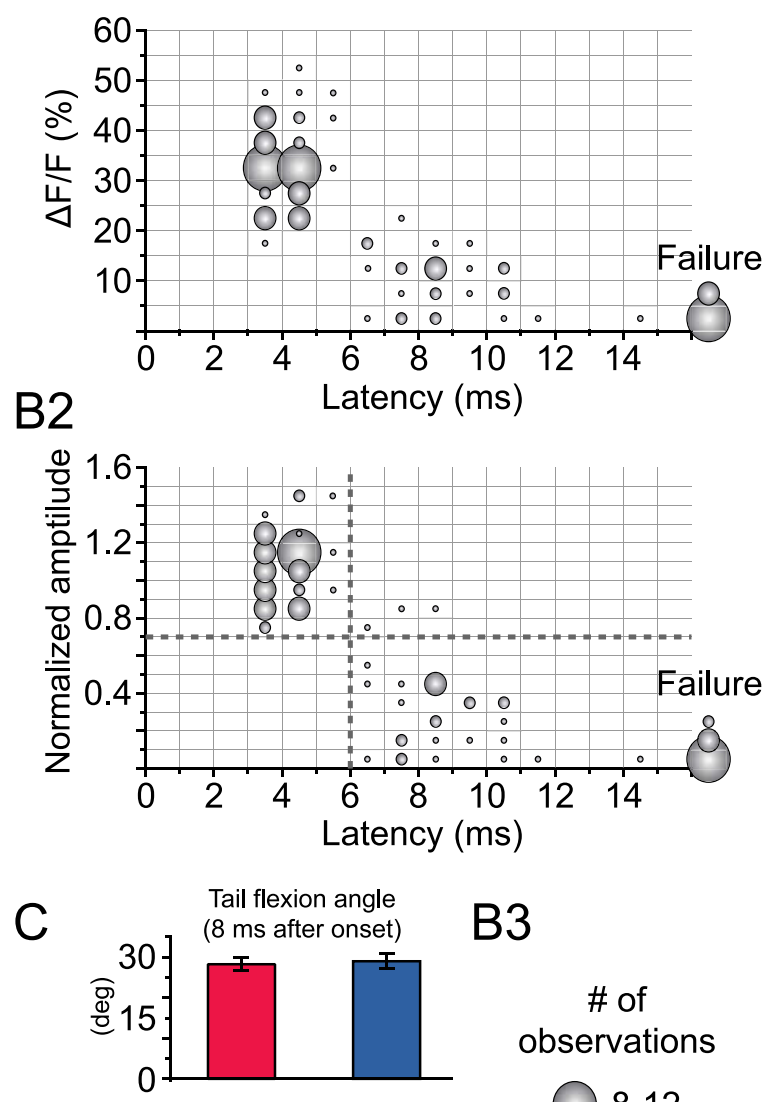

B3

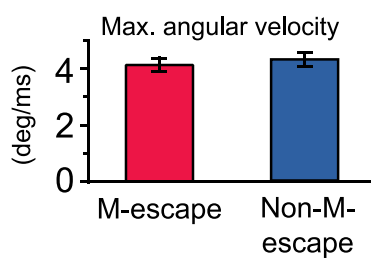

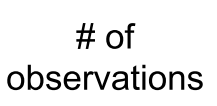
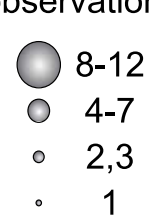

Figure 4. Single spiking of the M-cell tightly correlated with fast escape with short latency. $A$, Representative trajectories of tail flexion elicited by a water pulse applied to the OV. The tail flexion angle (ordinate) (measured as in Fig. 1(2) is plotted against the time after water pulse arrival (abscissa). Exemplified tail flips $(n=19)$ obtained from five fish (denoted by different symbols for each fish) are superimposed. Red and blue represent tail flips associated with (M-escapes) and without M-cell firing (non-M-escapes), respectively (see below). $\boldsymbol{B}$, The relationship between escape onset latency (abscissa) in response to the $\mathrm{OV}$ stimulation and accompanying fluorescence response amplitude of the ipsilateral M-cell (ordinate) is illustrated in bubble charts ( $n=91 ; 17$ fish), with the size of the bubbles representing the number of observations in each bin (B3). The fractional increase in fluorescence intensity $(\Delta F / F)(B 1)$ (bin size, $5 \%$ and $1 \mathrm{~ms}$ ) and the value normalized by the $A D$ spike amplitude ( $\times A D)$ (B2) (bin size, $0.1 \times A D$ and $1 \mathrm{~ms}$ ) are displayed. The majority of fast escapes started with short latency (3-5 $\mathrm{ms}$ ) and were accompanied with a large apparent increase in fluorescence in the M-cell, which was comparable with that of an $\mathrm{AD}$ action potential, indicating that a single spiking of the $\mathrm{M}$-cell the hair cells started regenerating (Harris et al., 2003). Successful elimination of the lateral line hair cells was verified by staining them through incubation in $10 \%$ HBSS containing 2-[4-(dimethylamino)styryl]- $N$ ethylpyridinium iodide (DASPEI) (0.05\%; Invitrogen) for $20 \mathrm{~min}$.

Statistics. Results were presented as the mean \pm SEM. The statistical significance was assessed using the Student's $t$ test after verifying the normality of the distributions by the Kolmogorov-Smirnov test $(p>$ $0.05)$ and the equality of the variance with the $F$ test $(p>0.05)$, unless otherwise noted.

\section{Results}

Escape response of partially restrained larvae

A key aspect of this study was reproduction of the fast escape in the partially restrained (semifixed) larval zebrafish in which $\mathrm{Ca}^{2+}$ imaging of hindbrain RSNs was performed. We examined the tail movements elicited by applying a water pulse stimulus to the OV on one side of the semifixed larva and compared them with those of the fast escape in freely moving (unrestrained) fish (Kimmel et al., 1974, 1980; Liu and Fetcho, 1999; Budick and O’Malley, 2000; Burgess and Granato, 2007) (Fig. 1A,B). Both unrestrained and semifixed preparations exhibited tail flexions contralateral to the stimuli (20 of 22 responses and 96 of 101 responses, respectively). The time from the water pulse arrival to the tail movement onset (latency, 3-12, $5.7 \pm$ $0.6 \mathrm{~ms} ; 3-15,5.3 \pm 0.3 \mathrm{~ms}$, respectively) and angular velocity of the initial tail flexion $\left(20-48,31.5 \pm 1.5^{\circ} ; 17-41,29.5 \pm 0.5^{\circ}\right.$ during 8 $\mathrm{ms}$ after movement onset, respectively) were not significantly different (Fig. 1C) ( $p>0.1$, Mann-Whitney $U$ test) between the two preparations. Thus, the tail flips observed in the semifixed larva reflect the tail movements during the initial phase of fast escape.

These tail responses started within $15 \mathrm{~ms}$ after the stimulus arrival. In a few cases, behavioral responses with long latencies ( $>15 \mathrm{~ms}, 24-92 \mathrm{~ms}$ ) also occurred in both preparations. However, we excluded them from the following analysis, because they showed significantly slower initial bending $\left(13.9 \pm 4.6^{\circ}, n=4\right.$; $10.3 \pm 2.4^{\circ}, n=8$, during the initial $8 \mathrm{~ms}$ in unrestrained and semifixed preparations, respectively; $p<0.001$ ) than during the short-latency fast responses, as reported previously (Burgess and Granato, 2007).

\section{Single spiking of the M-cell associated with initiation of fast escape with short latency}

Field potential recordings of $\mathrm{M}$-cell spiking in freely moving goldfish have shown that onset of fast escape is closely correlated with preceding firing of the M-cell (Zottoli, 1977; Eaton et al., 1981, 1988; Weiss et al., 2006). Here, we examined the correlation by $\mathrm{Ca}^{2+}$ imaging of the $\mathrm{M}$-cells during the tail flip of the semifixed larva. The M-cells were retrogradely labeled with a $\mathrm{Ca}^{2+}$ indicator (Oregon Green BAPTA-1 dextran) and were imaged with confocal microscopy (FV300) (see Materials and Methods) as exemplified in Figures 2 and 3. The majority of the fast escapes elicited by a water pulse applied to an OV to activate auditory or vestibular sensory afferents were associated with an observed increase in fluorescence $(\Delta F / F)$ in the ipsilateral M-cell, whereas no

$\leftarrow$

was associated with the initiation of fast escape with short latency $(>0.7 \times A D$; denoted M-escapes) (see Results). In particular, fast escapes starting within $6 \mathrm{~ms}$ after stimulus onset were always associated with an M-cell spike. In contrast, fast escapes without an M-cell spike, indicated by fluorescence responses smaller than the AD action potential $(<0.7 \times A D$; denoted non-M-escapes), started with latency $>6 \mathrm{~ms}$. In addition, when escape failed to occur (failure), the M-cell never fired. The vertical and horizontal gray dotted lines in $\boldsymbol{B} \mathbf{2}$ indicate $6 \mathrm{~ms}$ and $0.7 \times A D$, respectively. $C$, There was no significant difference in initial angle (during the initial $8 \mathrm{~ms}$; top) and maximal angular velocity (bottom) of the tail flexion between the M-escapes and the non-M-escapes. Error bars indicate SEM. 
or much smaller fluorescence responses were obtained in the contralateral M-cell (Fig. 2A,B). Typically, an increase of $>20 \%$ from the resting fluorescence intensity was observed in the ipsilateral $\mathrm{M}$-cell soma associated with the fast escape ( $n=60$ of $91 ; 17$ fish $)$.

To assess whether the fluorescence response of the $\mathrm{M}$-cell during the fast escape reflects spiking of the cell, we compared it with the fluorescence response of an $\mathrm{AD}$ action potential in the same cell. Application of electrical pulses with different intensities to the spinal cord induced fluorescence transients in the $\mathrm{M}$-cell in an allor-nothing manner with a steady amplitude (Fig. 2C) (peak $\Delta F / F, 30.9 \pm$ $1.6 \% ; 17$ cells), which was mediated by $\mathrm{Ca}^{2+}$ influx through voltage-gated calcium channels opened during an $\mathrm{AD}$ action potential (Takahashi et al., 2002). Thus, we defined the fluorescence response with an amplitude $>0.7$ times that of an $\mathrm{AD}$ spike ( $\times \mathrm{AD}$ ) as a sign of orthodromic spiking of the M-cell (see the summarized Fig. 4 B2). In the $\mathrm{M}$-cell, repetitive firing is suppressed by its powerful recurrent inhibitory circuit (see Discussion). Previously, it was shown that double AD stimulation elicits a $\mathrm{Ca}^{2+}$ signal in the $\mathrm{M}$-cell nearly twice as large as that resulting from single $\mathrm{AD}$ stimulation when the recurrent inhibition was blocked pharmacologically [Takahashi et al. (2002), their Fig. 7]. The fact that the sensory-evoked responses never reached twice that of an $\mathrm{AD}$ response $(<1.5 \times \mathrm{AD})$ suggests that the $\mathrm{M}$-cell fired once during the fast escape as observed electrophysiologically in goldfish (Zottoli, 1977; Eaton et al., 1981, 1988; Weiss et al., 2006).

Of 91 fast escapes obtained from 17 fish, 63 escapes were associated with a suprathreshold increase in fluorescence $(>0.7 \times \mathrm{AD})$ in the ipsilateral M-cell (peak $\Delta F / F, 18-51 \% ; 32.5 \pm 0.9 \% ; 0.74-1.50 \times \mathrm{AD} ; 1.04 \pm$ $0.02 \times \mathrm{AD})($ Fig. $4 A$, red; $B)$. They were denoted as M-escapes. $\mathrm{M}$-cell firing was never observed when an escape failed to occur at threshold (peak $\Delta F / F,<6.5 \% ; 2.2 \pm 0.6 \% ;<0.24 \times \mathrm{AD} ; 0.09 \pm$ $0.02 \times \mathrm{AD} ; n=17$ ) (Fig. $4 B$, failure) or subthreshold intensity (peak $\Delta F / F,<5.6 \% ; 2.4 \pm 0.6 \% ;<0.14 \times \mathrm{AD} ; 0.07 \pm 0.02 \times \mathrm{AD}$; $n=9$ ) of the water stimulus for the tail response. These findings support the previous notion that the $\mathrm{M}$-cell triggers a fast escape toward the contralateral side (Yasargil and Diamond, 1968; Zottoli, 1977; Eaton et al., 1981, 1988; Hackett and Faber, 1983; Hackett and Greenfield, 1986; Weiss et al., 2006). In some fast escape responses (28 of 91) of the same fish, however, the ipsilateral M-cell showed only subthreshold $(<0.7 \times \mathrm{AD})$ fluorescence responses (Figs. 3; $4 A$, blue, $B$ ) (peak $\Delta F / F,<16 \% ; 7.5 \pm 0.9 \%$; $<0.55 \times \mathrm{AD} ; 0.26 \pm 0.03 \times \mathrm{AD})$, indicating that the M-cell did not fire. The subthreshold increase in fluorescence may represent the $\mathrm{Ca}^{2+}$ influx associated with a postsynaptic response without spiking. These fast escapes were denoted as non-M-escapes.
A2

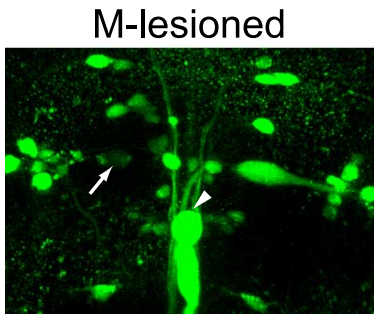

B
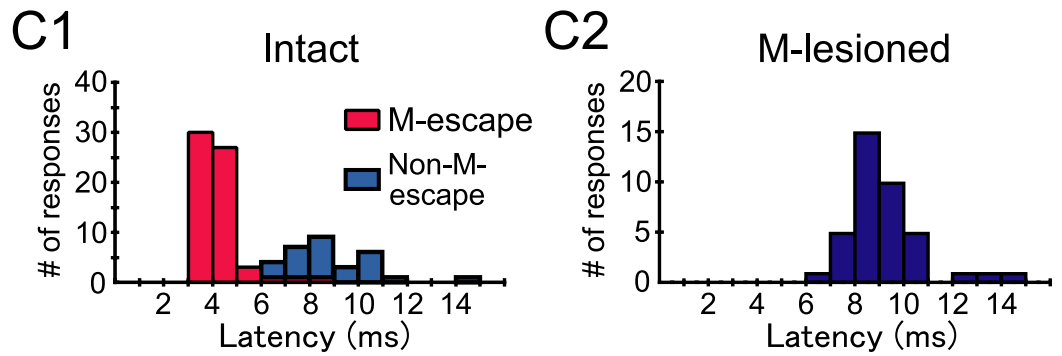

Figure 5. M-cells are necessary for initiating fast escape with short latency. $\boldsymbol{A}$, Fluorescence images of reticulospinal neurons soma and the stumped axon of the irradiated $\mathrm{M}$-cell (arrowhead) without effect on nearby neurons show that the M-cell was onset latencies of fast escapes elicited by the OV stimulation in intact (C1) or M-lesioned (C2) fish. C1, Fast escapes of intact fish simultaneously monitored. C2, After ablation of the M-cell, fast escape showed only delayed onset $>6 \mathrm{~ms}$.

There was a close correlation between firing of the ipsilateral $\mathrm{M}$-cell and the onset latency of the fast escape (Fig. $4 B$ ). It is clearly seen that $\mathrm{M}$-escapes displayed shorter latencies than nonM-escapes (average onset latency, $3.7 \pm 0.1$ and $8.4 \pm 0.3 \mathrm{~ms}$, respectively; $p<10^{-4}$, Mann-Whitney $U$ test) (Fig. 5C1). In particular, escapes with latencies $<6 \mathrm{~ms}$ were always accompanied with $\mathrm{M}$-cell firing.

Once the fast escape started, however, the trajectories of the initial tail flexion during $\mathrm{M}$ - and non-M-escapes were indistinguishable from each other (Fig. $4 A$ ). The tail flexion angles $\left(28.5 \pm 1.4\right.$ and $29.2 \pm 1.6^{\circ}$, during the initial $8 \mathrm{~ms}$; data from 12 fish that exhibited both $\mathrm{M}$ - and non-M-escapes, respectively) and maximum angular velocities $(4.2 \pm 0.2$ and $4.3 \pm 0.3 \% \mathrm{~ms}$, respectively) of the initial bending were the same as shown in Figure $4 C(p>0.1$, paired $t$ test). No significant correlations were observed between the onset latency and these kinematic parameters $(r=0.08$ and 0.02 , respectively; $p>0.7$ ) (Fig. 1C3), although the later phase of tail movement could not be mea- 
A
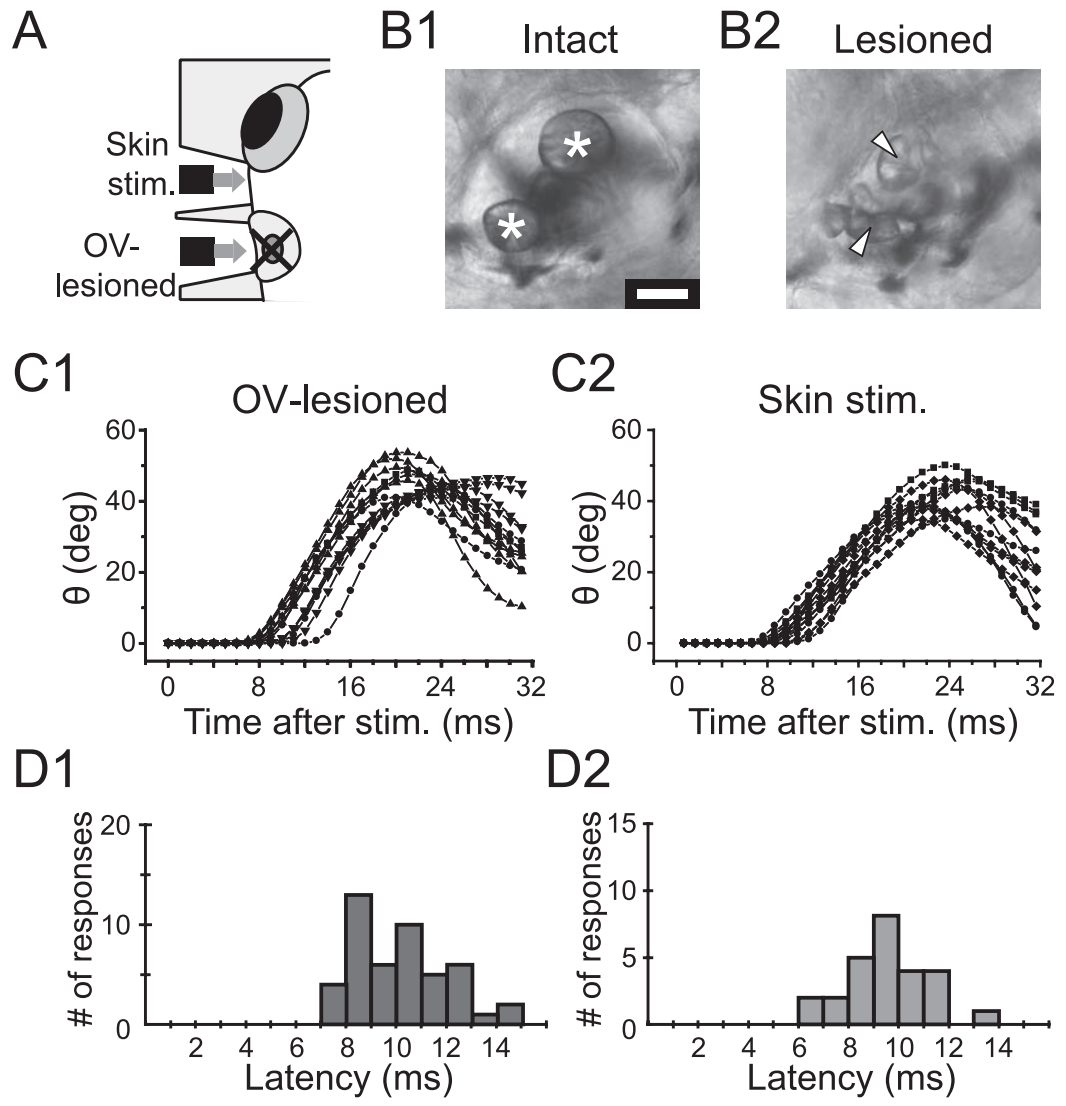

Figure 6. Escape response elicited by head-tactile stimulation. $A$, Tactile stimuli applied to head skin. (1) A water pulse was delivered to the $\mathrm{OV}$, but the otoliths were broken by laser pulses or the OV was eliminated (OV-lesioned). (2) A water pulse was applied to the head skin between an intact OV and eye (Skin stim.). $\boldsymbol{B}$, Lateral view of an OV before (B1) and after (B2) crushing two otoliths (asterisks) by laser pulse application in a 6 dpflarva. Cracked pieces of two otoliths are indicated by arrowheads in $\boldsymbol{B} \mathbf{2}$. Left is rostral, and up is dorsal. Scale bar, $50 \mu \mathrm{m}$. $\boldsymbol{C}$, Angle trajectories of the tail flexion in response to a water pulse stimulus applied to the lesioned OV (C1; 13 traces obtained from 4 fish) or the head skin of intact fish ( $\mathbf{C} ; 13$ traces obtained from 4 fish). The onset was always delayed. $\boldsymbol{D}$, Frequency distribution of the onset latency (D1, OV-lesioned; D2, Skin stim.). The response showed latencies $>6 \mathrm{~ms}$.

sured because the tail movement was restricted by the headembedding agar. Nor were any significant correlations observed between latency and kinematic parameters of tail movement in the unrestrained larvae (flexion angle during the initial $8 \mathrm{~ms}$, maximum angular velocity, maximal angle and duration of the initial bending; $r=-0.10,-0.05,-0.10$, and 0.04 , respectively; $p>0.6$ ). Thus, non-M-escapes showed fast escape movement similar to that of $\mathrm{M}$-escapes, but with a delay in the onset.

To assess whether M-cell firing is required for the initiation of escape with short latency (3-6 ms), we examined the effects of $\mathrm{M}$-cell ablation. After selective photoablation of retrogradely labeled M-cells (Fig. 5A) (Liu and Fetcho, 1999), fast escapes never started within $6 \mathrm{~ms}$ (Fig. $5 B, C 2$ ) (onset latency, $8.7 \pm 0.3 \mathrm{~ms} ; n=$ 39; five fish). In contrast, there were no apparent differences in the trajectories or velocities of tail movement between intact and ablated animals (tail flexion angle during the initial $8 \mathrm{~ms}, 26.8 \pm$ $3.1^{\circ}$; maximum angular velocity, $4.0 \pm 0.4^{\circ} / \mathrm{ms} ; p>0.4$ ). Hence, the $\mathrm{M}$-cell is indispensable for initiation of the fast escape with a short delay.

\section{Different sensory inputs initiate fast escape via different descending pathways}

Application of water pulses to the $\mathrm{OV}$, a premature organ of the inner ear, may activate inner ear hair cells and then statoacoustic nerve afferents. In addition, it may also activate other sensory nerves including the trigeminal sensory or lateral line (LL) nerve innervating the head skin surrounding the OV. The former senses the deflection of the head skin and the latter senses water flow at the skin surface via LL hair cells in neuromasts. To assess the contributions of these inputs to initiation of the fast escape, we examined the effects of lesioning the OV on the tail flip and M-cell firing. After the inner ear otoliths were laser-ablated (Fig. 6A,B) or the OV was surgically eliminated with a fine tungsten needle, the larvae exhibited abnormal swimming on their sides or back. However, a fast escape was still elicited in the semifixed preparation by a water pulse applied to the lesioned OV (OV-lesioned) (Fig. 6C1), indicating that tactile stimulation still elicited the escape. But the onset latency was longer than that of intact fish (Fig. 6D1) (9.7 $\pm 0.3 \mathrm{~ms} ; n=47 ; 10$ fish; $p<10^{-4}$, Mann-Whitney $U$ test). In contrast, the tail flexion angle (during the initial $\left.8 \mathrm{~ms}, 33.7 \pm 1.5^{\circ}\right)$ and maximum angular velocity $\left(4.9 \pm 0.4^{\circ} / \mathrm{ms}\right)$ observed in the OV-lesioned animal was similar to that in intact fish $(p>0.1)$. After the OV lesions, the M-cells exhibited only subthreshold fluorescence responses (Fig. $7 A, B 1)(\Delta F / F, 5.7 \pm 1.1 \%, 0.25 \pm 0.05 \times$ $\mathrm{AD} ; n=16$; five fish), whereas AD stimulation still elicited robust responses as in intact fish (Fig. $7 A$, inset) (peak $\Delta F / F$, $24.8 \pm 3.4 \%)$. A suprathreshold fluorescence response was never observed, even when the maximal pressure of the stimulus apparatus was applied (50-60 psi, approximately twofold to threefold higher than behavioral threshold; $n=5$; three fish). Nor were suprathreshold responses observed when the water pulse was applied to the head skin between an eye and OV in intact fish (Figs. $6 A, 7 B 2)(\Delta F / F, 7.0 \pm 1.7 \% ; 0.27 \pm 0.05 \times \mathrm{AD}$; $n=15$; four fish). As shown in Figure 6, C2 and D2, only delayed escape was elicited by the head skin stimulation (latency, $>6 \mathrm{~ms}$; $9.0 \pm 0.3 \mathrm{~ms} ; n=26$; six fish; $p<10^{-4}$, Mann-Whitney $U$ test), the trajectory of which was similar to that evoked by OV stimulation (tail flexion angle during the initial $8 \mathrm{~ms}, 27.9 \pm 1.1^{\circ}$; maximum angular velocity, $4.1 \pm 0.1 \% \mathrm{~ms} ; p>0.4)$. These data strongly suggest that activation of auditory or vestibular input is necessary to induce the $\mathrm{M}$-cell firing that elicits a fast escape with short latency (M-escape). In addition, sensory input from the head skin may preferentially elicit a non-M-escape.

Next, to examine whether the LL system was involved in initiating the fast escapes, we tested tail response and M-cell firing after pharmacological poisoning of the LL system with an aminoglycoside antibiotic, neomycin (300-500 $\mu \mathrm{M})$ (Harris et al., 2003). Because LL neuromasts are located only on the skin surface before $9 \mathrm{dpf}$ (Webb and Shirey, 2003), a styryl pyridium dye, DASPEI, was used to label the functional hair cells in the superficial neuromasts by direct permeation through their mechanotransduction channels (Balak et al., 1990; Nishikawa and Sasaki, 1996; Gale et al., 2001; Meyers et al., 2003). The complete loss of 
DASPEI-labeled neuromasts after neomycin treatment (supplemental Fig. $1 A$, available at www.jneurosci.org as supplemental material) indicates dysfunction or degeneration of LL hair cells (Harris et al., 2003; Murakami et al., 2003; Owens et al., 2007). However, both M- (onset latency, $3.8 \pm 0.2 ; n=13$ ) and nonM-escapes $(7.3 \pm 0.5 \mathrm{~ms} ; n=8)$ were still elicited by the OV stimulation as in the control (supplemental Fig. $1 B$, available at www.jneurosci.org as supplemental material) $(p>0.05$; three fish). Thus, it is unlikely that LL input makes a considerable contribution to the initiation of the fast escape. The effects of lesion of OV or LL input on the initiation of the tail flexion, as mentioned above, suggest that activation of the remaining sensory input, the trigeminal sensory nerve innervating head skin, triggers the delayed non-M-escape.

In contrast to head-tactile stimulus, water pulse application to the tail of the semifixed larva elicited the fluorescence response corresponding to a single spike in the ipsilateral M-cell in association with a fast escape (supplemental Fig. 2, available at www. jneurosci.org as supplemental material $)(\Delta F / F, 0.81-1.35 \times \mathrm{AD}$; $1.02 \pm 0.05 \times \mathrm{AD} ; 12$ of 24 fast escapes; seven fish), as suggested by a previous $\mathrm{Ca}^{2+}$ imaging study using a fully restrained preparation (O'Malley et al., 1996). Thus, tactile stimulation of tail skin can induce firing of the M-cell. Unlike head-tactile input, tailtactile input is transmitted to the M-cell through the sensory DRG neurons or the posterior LL system. In addition, the remaining tail responses represented non-M-escapes accompanied with only subthreshold fluorescence response in the $\mathrm{M}$-cell $(\Delta F / F,<0.47 \times \mathrm{AD} ; 0.30 \pm 0.04 \times \mathrm{AD} ; n=12)$. The appearance of non-M-escape was consistent with previous observations that tail-directed water pulses still elicited fast escape in larval zebrafish after lesioning of the M-cell (Liu and Fetcho, 1999). The onset latency of M-escape evoked by the tail stimulus (5.3 \pm 0.7 ms; $n=12$ ) was also shorter than that of non-M-escape ( $8.9 \pm$ $0.3 \mathrm{~ms} ; n=12 ; p<0.005$, Mann-Whitney $U$ test). The longer latency of M-escape evoked by tail stimulation than that evoked by OV stimulation ( $p<10^{-4}$, Mann-Whitney $U$ test) may be attributable to the longer conduction distance of tail-tactile input than that of acousticovestibular input to the M-cell.

\section{MiD3 $\mathrm{cm}$ activity is complementary to the M-cell during fast escapes}

It has been demonstrated that a distributed population of hindbrain RSNs are activated together with the M-cell in response to head tapping in zebrafish restrained in agar (Gahtan et al., 2002). Among the RSNs, the segmental homologs of the M-cell (the MiD2 $\mathrm{cm}$ and $\mathrm{MiD} 3 \mathrm{~cm}$ cells) are thought to be coactivated with the ipsilateral $\mathrm{M}$-cell in response to the ipsilateral head-tap stimulus (O'Malley et al., 1996). From a lesion study, the series of homologs are suggested to be involved in the expression of fast escape (Liu and Fetcho, 1999). Here, we monitored the activity of $\mathrm{MiD} 2 \mathrm{~cm}$ and $\mathrm{MiD} 3 \mathrm{~cm}$ during fast escapes.

As in the case of the M-cell, a single electrical shock of the spinal cord evoked a transient fluorescent response, associated with an $\mathrm{AD}$ action potential, in $\mathrm{MiD} 3 \mathrm{~cm}$ in an all-or-nothing manner but with a much smaller amplitude than the M-cell (Fig. $8 A 1, A 2)(\Delta F / F, 2.2 \pm 0.2 \%$; eight cells) (for details, see Materials and Methods). When pulse trains were applied, a stepwise increase in the amplitude of the fluorescence response was observed against the number of stimulus pulses (Fig. 8A3) (delivered at the suprathreshold strength at $50 \mathrm{~ms}$ intervals; four cells), suggesting summation of $\mathrm{Ca}^{2+}$ responses evoked by each stimulus pulse.

Significant fluorescence responses in the ipsilateral $\mathrm{MiD} 3 \mathrm{~cm}$ were elicited by either OV or head skin stimulation on one side
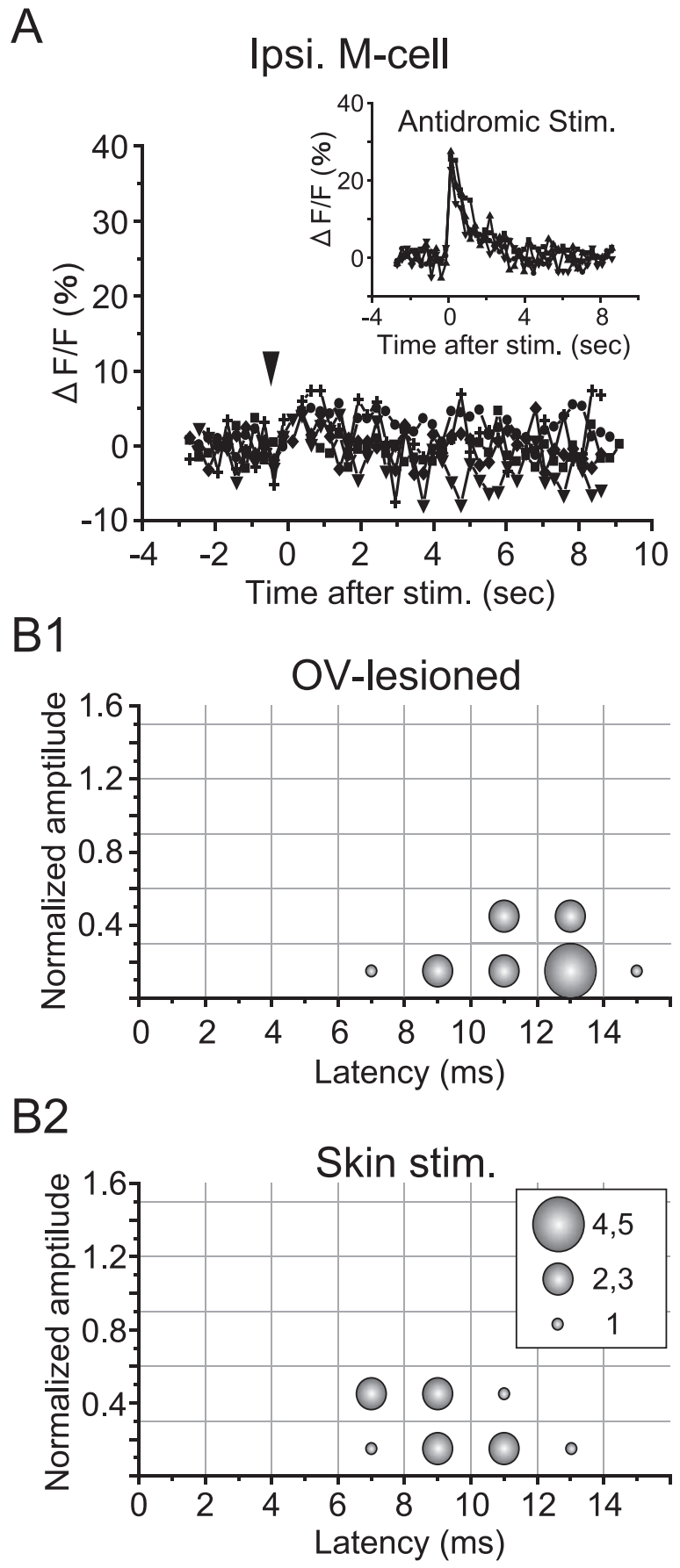

Figure 7. Sensory input from head skin preferentially initiates non-M-escape. $\boldsymbol{A}$, Water pulse stimulus applied to the lesioned $\mathrm{OV}$ produced only subthreshold fluorescence responses in the ipsilateral M-cell during fast escape (7 traces), whereas the M-cell exhibited robust fluorescence responses to the AD stimulation applied to the spinal cord (inset). $B$, Bubble chart representation of the relationship between the amplitude of the fluorescence response of the $\mathrm{M}$-cell and the onset latency of the fast escape elicited by a water pulse applied to the lesioned OV (B1) or the head skin (B2). In either case, fast escape was not elicited within $6 \mathrm{~ms}$, and only a small increase in fluorescence $(<0.6 \times A D)$ was observed in the ipsilateral M-cell. Bin size: $0.3 \times A D$; $2 \mathrm{~ms}$. The inset in $\boldsymbol{B 2}$, showing the number of observations, also applies to $\boldsymbol{B} \mathbf{1}$.

(11 fish). Interestingly, the amplitude was significantly smaller when the tail flip started within $6 \mathrm{~ms}$ than when it started with a longer delay (Fig. $8 B)(\Delta F / F, 2.7 \pm 0.4$ and $8.2 \pm 0.5 \% ; n=45$ and 17, respectively; $\left.p<10^{-8}\right)$. As shown in Figure $8 D$, the latter response was a few times larger than that evoked by a single $\mathrm{AD}$ stimulus (3.6 $\pm 0.4 \times \mathrm{AD} ; n=9$, respectively), suggesting that 


\section{MiD3cm (Antidromic Stim.)}

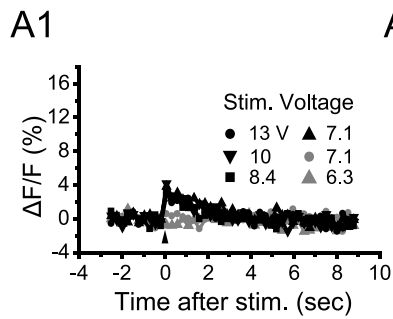

A2

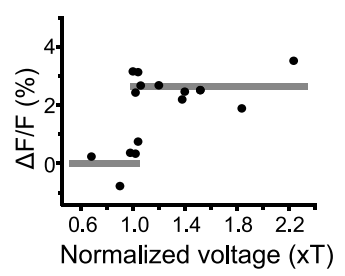

A3

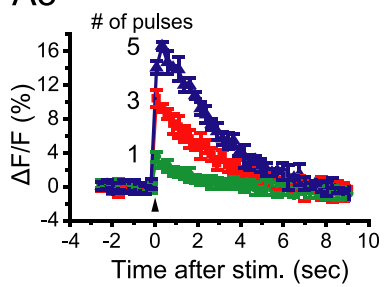

Ipsi. MiD3cm (Water Pulse Stim.)

B

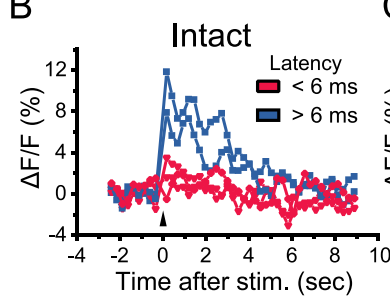

C

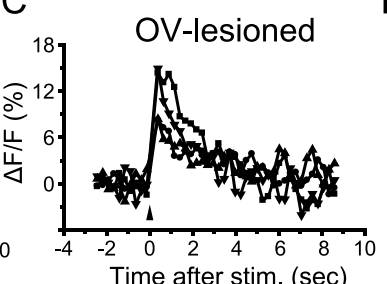

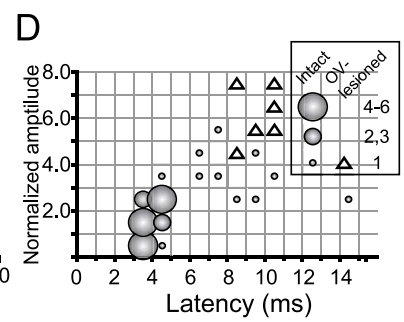

Figure 8. $\mathrm{Ca}^{2+}$ responses of $\mathrm{MiD} 3 \mathrm{~cm}$ elicited by stimulation of the inner ear or head skin. $\boldsymbol{A}$, Fluorescence responses of a $M i D 3 \mathrm{~cm}$ associated with antidromic action potential. $\boldsymbol{A} 1$, Electrical stimulation of the spinal cord induced fluorescence response in the MiD3cm in an all-or-nothing manner with changes in stimulus voltage, indicating that single antidromic action potential was elicited as in the M-cell (Fig. 2C). Note that the amplitude of the MiD3cm response was apparently smaller than that of the M-cell. A2, Amplitudes of fluorescence responses are plotted against stimulus voltage (normalized to the threshold voltage, $T$ ) as in Figure 2C2. The left and right gray lines indicate 0 and $2.6 \%$, respectively. A3, As the number of stimulus pulses was increased at an intensity of $1.1 T$ with an interstimulus interval of $50 \mathrm{~ms}$, the response amplitude increased stepwise, indicating multiple firing of the MiD $3 \mathrm{~cm}$. Average amplitudes (mean $\pm S D ; n=4-7$ for each trace) of the fluorescence transients elicited by one, three, and five pulses are plotted, respectively. $\boldsymbol{B}$, Fluorescence responses in a $M i D 3 \mathrm{~cm}$, the same cell shown in $\boldsymbol{A 1}$, elicited by the water pulse applied to the ipsilateral $\mathrm{OV}$ of an intact animal. Five responses associated with fast escape are superimposed, demonstrating that the response amplitudes were smaller when the escapes started with shorter $(<6 \mathrm{~ms}$; red) latencies than when the escape started with longer ( $>6 \mathrm{~ms}$; blue) latencies. C, A significant increase in fluorescence in MiD3cm was also elicited in the OV-lesioned fish. Four traces obtained from two fish are superimposed. $\boldsymbol{D}$, Normalized amplitude of fluorescence response in MiD3cm during fast escape. Data are represented in a bubble chart as shown previously. In contrast to the $\mathrm{M}$-cell, the responses in MiD3cm evoked by OV or head skin stimulation in both intact (circles) and OV-ablated fish (triangles) were several times larger than those evoked by single AD stimulation, especially when the escape started $>6 \mathrm{~ms}$ after stimulus arrival.

were observed with short-latency $(<6 \mathrm{~ms})$ escape, whereas the subthreshold response in the M-cell $(8.3 \pm 0.9 \% ; n=46)$ and the large response in $\mathrm{MiD} 3 \mathrm{~cm}$ (see above) were observed with the delayed fast escape (>6 ms; OV intact). The latter was also observed for the delayed fast escape after the OV was lesioned (OV lesioned) (see above). These results above strongly suggest that greater activation of $\mathrm{MiD} 3 \mathrm{~cm}$ is involved in the non-M-escape evoked by tactile stimulus. Furthermore, $\mathrm{MiD} 3 \mathrm{~cm}$ did not show apparent fluorescence changes $(\Delta F / F,<1.3 \% ; 0.6 \pm 0.4 \% ; n=5)$ and none appeared to fire $(<0.4 \times \mathrm{AD}$; $0.28 \pm 0.11 \times \mathrm{AD} ; n=3)$ in response to a water pulse with subthreshold intensity for tail response.

The ipsilateral MiD2 $\mathrm{cm}$ of intact fish (eight fish) showed a tendency similar to MiD3cm: smaller $\mathrm{Ca}^{2+}$ response during M-escape $(\Delta F / F, 1.1 \pm 0.3 \% ; n=24)$ and larger response during non-M-escape $(\Delta F / F, 2.0 \pm 1.2 \% ; n=8)$. Despite the fact that the amplitude of a single AD response was very small $(\Delta F / F, 1.4 \pm 0.3 \%$; five cells), MiD2 $\mathrm{cm}$ apparently fired fewer action potentials in M-escape $(0.8 \pm 1.3 \times$ $\mathrm{AD} ; n=3)$ than in non-M-escape (1.8 \pm $0.7 \times \mathrm{AD} ; n=4)$. However, both the raw and normalized amplitudes of fluorescence response were too small to compare statistically ( $p>0.2$, Welch's $t$ test). Overall, the M-cell and its homologs are suggested to act cooperatively as a functional group, as reported previously (O'Malley et al., 1996); however, the homologs appeared to behave in a manner complemen-

multiple firing of $\mathrm{MiD} 3 \mathrm{~cm}$ occurred during the delayed fast escape. In contrast, the former responses were as small as an $\mathrm{AD}$ spike on average $(1.3 \pm 0.2 \times \mathrm{AD} ; n=20)$. Interestingly, when the water pulses were applied to the lesioned OV, the ipsilateral MiD3cm exhibited $\mathrm{Ca}^{2+}$ responses (Fig. $\left.8 C\right)(8.5 \pm 0.8 \% ; n=7$; four fish) with manyfold larger amplitudes than those of an $\mathrm{AD}$ spike (Fig. $8 D)(6.2 \pm 0.5 \times \mathrm{AD} ; n=6$; three fish), suggesting multiple spiking. Thus, the relationship between MiD3cm activity and the behavioral onset latency seems inverse to that of the M-cell.

This relationship was directly examined by simultaneous $\mathrm{Ca}^{2+}$ imaging of the M-cell and MiD3 $\mathrm{cm}$ during fast escape using a high-speed confocal microscope equipped with a high-speed focus control on the objective lens to alternately monitor the two cells located at different depths (Fig. 9A) (for details, see Materials and Methods). Figure 9, $B$ and $C$, shows the complementary pattern of activation in the $\mathrm{M}$-cell and $\mathrm{MiD} 3 \mathrm{~cm}$ during the fast escape (four pairs) when a water pulse was applied to the ipsilateral OV. MiD3cm exhibited only a small response when the $\mathrm{M}$-cell fired (M-escape) but a large response when the M-cell did not fire (non-M-escape). Figure 9D summarizes the relationships between escape onset latency and the amplitude of the fluorescence response of the $\mathrm{M}$-cell and $\mathrm{MiD} 3 \mathrm{~cm}$, demonstrating that the suprathreshold fluorescence response in the M-cell (33.1 \pm $0.9 \% ; n=60)$ and the small response in MiD3cm (see above) tary to M-cell firing during fast escape.

Finally, we examined the possibility that $\mathrm{MiD} 3 \mathrm{~cm}$ is involved in directional control of escape, as hypothesized by Foreman and Eaton (1993). The escape trajectory was previously described with kinematic parameters on body bending during the initial turn and timing of the counter turn (Foreman and Eaton, 1993). In the present study, although the head of zebrafish was embedded, the tail showed various flexion angles to some extent, which probably represent variety in activity of the trunk muscle. We compared tail flexion angle and fluorescence response of the MiD3cm (supplemental Fig. 3, available at www.jneurosci.org as supplemental material). In the M-escapes, larger fluorescence responses of the MiD3cm $(\Delta F / F, 3.9 \pm 0.7 \% ; n=18)$ were observed in association with large tail flexions (maximum flexion angle, $\left.>35^{\circ}\right)$ than in the case of small tail flexions $\left(<35^{\circ} ; \Delta F / F\right.$, $1.3 \pm 0.4 \% ; n=25 ; p<10^{-3}$, Welch's $t$ test). The difference was also significant when they were normalized by the amplitude of $\mathrm{AD}$ response $(1.9 \pm 0.3 \times \mathrm{AD}$ and $0.6 \pm 0.3 \times \mathrm{AD} ; n=17$ and 5 , respectively; $p<0.05)$. These results indicate that more spikes in $\mathrm{MiD} 3 \mathrm{~cm}$ are associated with larger initial bending of the tail during M-escape. In fast escapes with delayed onset ( $>6 \mathrm{~ms}$ ), which were virtually identical to the non-M-escapes, however, there was no significant difference between the responses of the MiD3 $\mathrm{cm}$ associated with large $\left(>35^{\circ} ; \Delta F / F, 8.3 \pm 0.8 \%\right.$ and $3.0 \pm 0.7 \times$ $\mathrm{AD} ; n=9$ and 6 , respectively) and small tail flexions $\left(<35^{\circ} ; \Delta F / F\right.$, 
A1

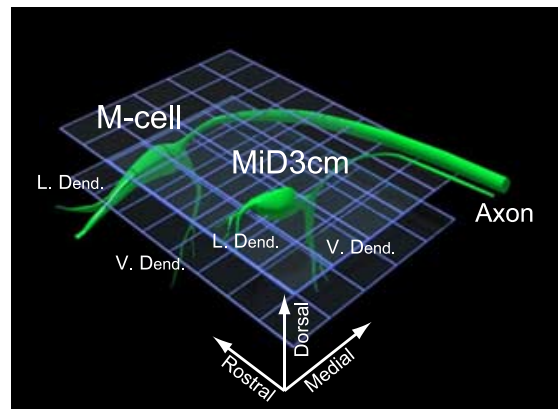

A2

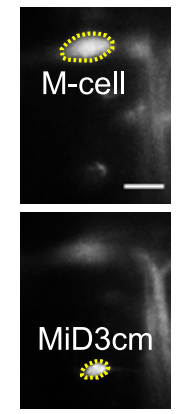

$\mathrm{B}$

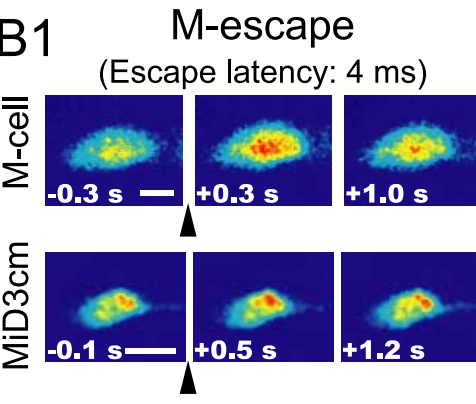

C

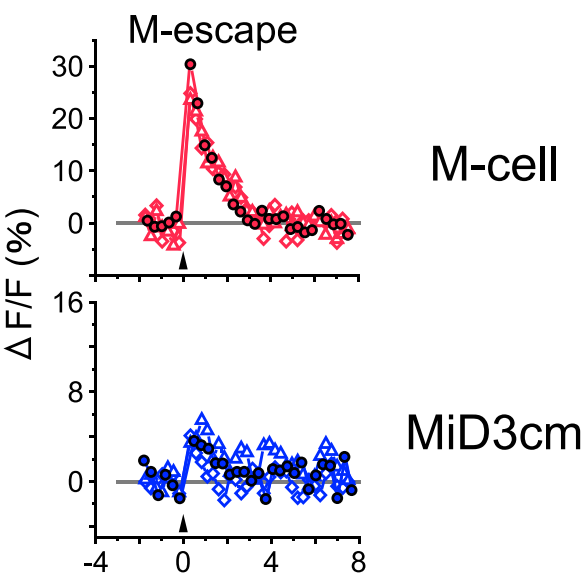

Time after stim. (sec)

$\mathrm{D}$

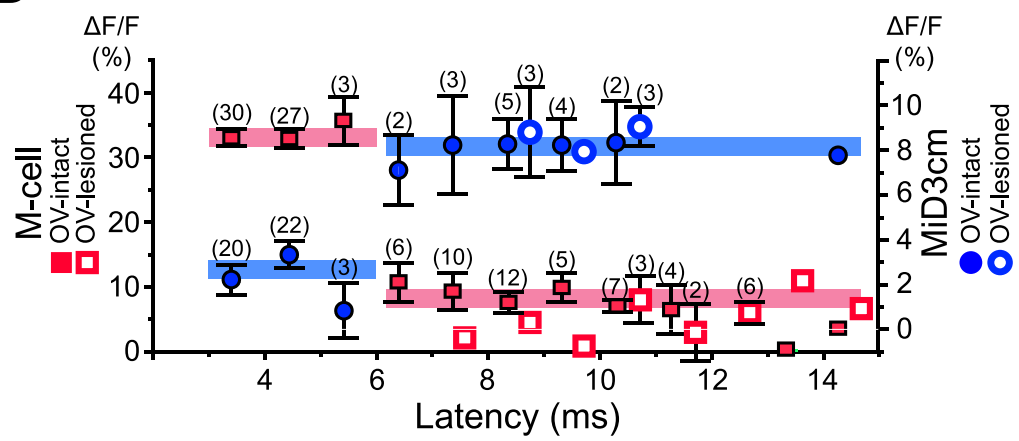

Figure 9. Complementary relationship between activities of the $\mathrm{M}$-cell and $\mathrm{MiD} 3 \mathrm{~cm}$ during fast escape. $\mathbf{A 1}$, Alternative $\mathrm{Ca}^{2+}$ imaging of the M-cell and MID3cm was performed by switching two focal planes (gratings) at $7 \mathrm{~Hz}$ with a piezo-driven objective lens. Ventral ( $\mathrm{V}$.) and lateral (L.) dendrites (Dend.) and axons are indicated. A2, The brightest plane of MiD3cm soma (bottom) was $16 \mu \mathrm{m}$ dorsal to that of M-cell soma (top). Fluorescence intensities of the somata (the area in the yellow dashed lines) are quantified in C. Scale bar, $20 \mu \mathrm{m}$. B, Pseudocolored images of the somata of the M-cell (top) and MiD $3 \mathrm{~cm}$ (bottom), the same pair as shown in $\mathbf{A 2}$, before ( -0.3 and $-0.1 \mathrm{~s}$ ) and after ( +0.3 to $+1.2 \mathrm{~s}$ ) applying the water pulse stimulus to the $0 \mathrm{~V}$ (arrowheads). $B 1$, When escape occurred with short (4 ms) latency, the M-cell showed a large fluorescence increase (M-escape), whereas MiD3cm showed only a small response. $\boldsymbol{B 2}$, In contrast, when escape started with longer (10 ms) latency, the M-cell did not show apparent response (non-M-escape), whereas the MiD3cm showed a significantly larger increase in fluorescence than in $\boldsymbol{B} 1$. Color scales and scale bars $(10 \mu \mathrm{m})$ apply to both $\boldsymbol{B} 1$ and $\boldsymbol{B 2}$. C, Quantification of the change in fluorescence intensity of two pairs (filled and open symbols for each pair) of M-cell (top traces) and MiD3 $\mathrm{cm}$ (bottom traces) during three M-escapes (left column) and two
$8.8 \pm 1.4 \%$ and $3.5 \pm 0.5 \times \mathrm{AD} ; n=8$ and 3 , respectively; $p>0.5$ ), probably because bursting of the $\mathrm{MiD} 3 \mathrm{~cm}$ at the initiation of non-M-escape masked the difference in fluorescence response associated with that in amplitude of the following tail flexion.

\section{Discussion}

In vivo $\mathrm{Ca}^{2+}$ imaging of the $\mathrm{M}$-series neurons during fast escape in partially restrained larval zebrafish and the effect of lesioning sensory inputs showed that single spiking of one of the paired M-cells initiates a fast escape (M-escape) with short latency in response to auditory or vestibular inputs. In contrast, a delayed fast escape elicited by head-tactile input occurred without M-cell firing (non-M-escape), in which MiD3 $\mathrm{cm}$ was more involved than in M-escape.

\section{M-escape versus non-M-escape in intact fish}

The suprathreshold fluorescence response of the M-cell $(>0.7 \times \mathrm{AD})$ elicited by the water pulse stimulus represents generation of an orthodromic action potential, because its amplitude was similar to that evoked by a single AD spike and was distinguishable from the subthreshold $\mathrm{Ca}^{2+}$ response (Figs. 2-4). Simultaneous $\mathrm{Ca}^{2+}$ imaging and whole-cell recording have demonstrated that the somatic $\mathrm{Ca}^{2+}$ increase associated with an action potential is much larger than that with subthreshold depolarization (Smetters et al., 1999; Viana di Prisco and Alford, 2004; Berger et al., 2007). Single spiking of the M-cell is supported by the previous observations: (1) the M-cell is prevented from firing repetitively by a powerful recurrent feedback inhibitory circuit (Furukawa and Furshpan, 1963; Faber and Korn, 1978) and ex-

\footnotetext{
$\leftarrow$

non-M-escapes (right column). Responses obtained in the same trial are shown by the same symbol. The trials shown in $B 1$ and $\mathbf{B 2}$ are indicated by circles and squares, respectively. The response amplitude of $\mathrm{MiD} 3 \mathrm{~cm}$ was complementary to that of the M-cell. The gray lines indicate $0 \%$. D, Relationships between onset latency of escape and amplitude of fluorescence response elicited in the $\mathrm{M}$-cell (red squares) and MiD3cm (blue circles) of intact (filled symbols) or OV-lesioned (open symbols) fish. In intact fish, escapes with short latency ( $<6 \mathrm{~ms}$ ) were accompanied with M-cell firing (see Results) and a small response in MiD3cm, whereas in the case of escape with delayed ( $>6 \mathrm{~ms}$ ) latency, the M-cell did not fire and MiD3cm showed a larger response. The number of trials is denoted above the error bar. Error bars indicate SEM. Left and right calibrations apply to the $\mathrm{M}$-cell and $M i D 3 \mathrm{~cm}$, respectively. Red and blue horizontal bars represent average response amplitudes of the M-cell and MiD3cm, respectively, for fast escape with short ( $<6 \mathrm{~ms}$; left bars) or delayed $(>6$ $\mathrm{ms}$; right bars) latency in intact animals.
} 
pression of low-threshold potassium channels as shown in goldfish (Nakayama and Oda, 2004); (2) the recurrent inhibitory circuit was also demonstrated in both adult and larval zebrafish (Hatta and Korn, 1998; Takahashi et al., 2002); and (3) repetitive firing was observed in goldfish only when the recurrent inhibitory circuit or the low-threshold potassium channel was blocked pharmacologically (Furukawa et al., 1964; Nakayama and Oda, 2004).

From the tight correlation between M-cell firing and initiation of the fast escape (Fig. 4) together with the effect of M-cell lesioning on the escape onset latency (Fig. 5), we conclude that $\mathrm{M}$-cell firing is necessary to initiate fast escape with short latency $(<6 \mathrm{~ms})$ as shown in goldfish (Eaton et al., 1982; DiDomenico et al., 1988; Zottoli et al., 1999). A previous study using unrestrained larval zebrafish showed delay in the onset of escape elicited by a head-directed water pulse after lesioning of the M-cell (2.7 or 3.9 $\mathrm{ms}$ in prelesion and $4.6 \mathrm{~ms}$ in postlesion experiments), although it was not statistically significant (Liu and Fetcho, 1999). The lack of significance is probably because the water stimulus hit the OV or head skin by chance, which was critical to induce M-escape (Figs. 4, 7), or because the distance between the stimulus apparatus and the fish varied among trials and the water pulse often pushed the freely swimming larva, making it difficult to determine the escape onset latency.

Here, fast tail flexion without M-cell firing (Figs. 3, 4) provided the first direct evidence for non-M-escape in intact fish, which was originally indicated by observing the body twitch response of fully restrained larval zebrafish (Eaton et al., 1977, 1984). The shorter latency of the M-escape is explained by output properties of the M-cell. First, conduction velocity of the thick $\mathrm{M}$-axon is the highest in hindbrain descending neurons (Furshpan and Furukawa, 1962; Eaton and Farley, 1975; Hatta and Korn, 1998). We calculated the spike conduction times as 1.1 $\mathrm{ms}$ and $2.2 \mathrm{~ms}$ for the M-cell and non-M-cells, respectively, from the conduction velocities ( 3.0 and $1.5 \mathrm{~m} / \mathrm{s}$, respectively) (from Eaton and Farley, 1975) and the total length $(3.3 \mathrm{~mm}$ ) of their axons. Second, single spiking of the M-cell is sufficient to evoke a trunk muscle contraction (Nissanov et al., 1990), whereas bursting of non-M-cells, such as MiD3cm shown in Figures 8 and 9, may be necessary to evoke the muscle contraction. It has been demonstrated that the M-cell homologs burst at a frequency dependent on the depolarization amplitude (Nakayama and Oda, 2004).

The different efficiency of the two systems may result from the following morphological difference: the M-axon has short unbranched axon collaterals to make effective direct contacts with primary motoneurons at the initial segment (Fetcho, 1991). In contrast, the axon of $\mathrm{MiD} 3 \mathrm{~cm}$ exhibits extensive terminal arbors dorsally within the sagittal plane (Gahtan and O'Malley, 2003), suggesting that it connects directly but less effectively to motoneurons at the somatodendritic region than does the M-cell, or that it connects indirectly via interneurons. Similar kinematics of $\mathrm{M}$ - and non-M-escapes indicates that similar motoneuron pools are activated through a common spinal network. It still remains to be examined whether sensory input activates the M-cell with shorter delay than it does non-M-cells.

\section{Different sensory inputs initiate fast escape via different pathways}

In the present study, an M-escape occurred only when the water pulse was applied to an OV (Figs. 4, 6, 7), suggesting that acousticovestibular input induces M-cell firing in larval zebrafish, as in adult goldfish (Faber and Korn, 1978; Oda et al., 1998; Nakayama and Oda, 2004) and zebrafish (Hatta and Korn, 1998). Acousticovestibular input might also elicit non-M-escape in intact fish. However, vibratory stimulus was virtually unable to induce fast escape in M-cell-ablated zebrafish larva, but elicited slow escape with long latency ( $>15 \mathrm{~ms}$ ) (Burgess and Granato, 2007) (see also Kimmel et al., 1980). In the present study, slow tail movement with long latency $(>15 \mathrm{~ms})$ was observed also in intact semifixed larva, but was never associated with M-cell firing (data not shown). Thus, acousticovestibular input can elicit either fast escape via $\mathrm{M}$-cell firing or slow escape without $\mathrm{M}$-cell firing in larval zebrafish.

Head skin stimulation and the effects of OV ablation suggest that head-tactile input preferentially evokes non-M-escape (Figs. $6,7)$. However, the M-cell receives direct synaptic input from the trigeminal and LL sensory nerves, as well as the statoacoustic nerve (Kimmel et al., 1990), either of which could be activated by head stimulus. The lack of M-escape on head skin stimulation indicates that head-tactile input is insufficient to induce M-cell firing. This may at least partly result from the low input resistance of the large-sized M-cell. The trigeminal nerve runs caudally through the hindbrain and synapses onto the M-cell lateral dendrite with a small contact region (Kimmel et al., 1981), but in contrast, the statoacoustic nerve terminates over a large portion of the lateral dendrite of the M-cell (Faber and Korn, 1978; Szabo et al., 2007). Instead, the trigeminal nerve possibly synapses onto the dendrites of smaller RSNs (Kimmel et al., 1985) such as the $\mathrm{M}$-cell homologs and activates them to evoke non-M-escape.

\section{Relationship of Mauthner and non-Mauthner circuits}

Although MiD3cm fired in both $\mathrm{M}$ - and non-M-escapes, fluorescence response of $\mathrm{MiD} 3 \mathrm{~cm}$ was suppressed during $\mathrm{M}$-escape. This may be explained by that the acousticovestivular input eliciting $\mathrm{M}$-cell firing is not effective enough to activate $\mathrm{MiD} 3 \mathrm{~cm}$ as shown previously (Nakayama and Oda, 2004) or that the M-cell inhibits the ipsilateral MiD3 $\mathrm{cm}$ through inhibitory interneurons as observed in goldfish (Oda and Nakayama, 2003; Neki et al., 2007). The Mauthner-derived inhibition of non-M-escape pathway proposes that hierarchical organization of the hindbrain RSNs should prioritize acousticovestibular input over headtactile input for initiating fast escape.

It is noteworthy that, in zebrafish, the first observed escape during development is elicited by tactile stimulus to the head or tail [at $21 \mathrm{~h}$ postfertilization (hpf)] (Saint-Amant and Drapeau, 1998), whereas the escape elicited by auditory or vibratory stimulus appears much later (cf. Kimmel et al., 1974) (>72 hpf for larvae raised at $25^{\circ} \mathrm{C}$ ). The trigeminal input may be capable of firing the RSNs including the M-cell early in development (Eaton et al., 1977), although it may become insufficient to fire the M-cell later in development, as discussed above. The statoacoustic nerve inputs from the inner ear continuously develop connections with the M-cell to fire it effectively. Thus, teleost fishes, so-called hearing specialists (Popper and Fay, 1999) such as zebrafish and goldfish, acquire the acoustically evoked M-escape system in addition to the tactile-evoked non-M-system later in development to escape as quickly as possible from a hostile sound source before it reaches and injures the fish.

\section{References}

Balak KJ, Corwin JT, Jones JE (1990) Regenerated hair cells can originate from supporting cell progeny: evidence from phototoxicity and laser ablation experiments in the lateral line system. J Neurosci 10:2502-2512.

Berger T, Borgdorff A, Crochet S, Neubauer FB, Lefort S, Fauvet B, Ferezou I, Carleton A, Lüscher HR, Petersen CC (2007) Combined voltage and calcium epifluorescence imaging in vitro and in vivo reveals subthreshold 
and suprathreshold dynamics of mouse barrel cortex. J Neurophysiol 97:3751-3762.

Bhatt DH, McLean DL, Hale ME, Fetcho JR (2007) Grading movement strength by changes in firing intensity versus recruitment of spinal interneurons. Neuron 53:91-102.

Budick SA, O'Malley DM (2000) Locomotor repertoire of the larval zebrafish: swimming, turning and prey capture. J Exp Biol 203:2565-2579.

Burgess HA, Granato M (2007) Sensorimotor gating in larval zebrafish. J Neurosci 27:4984-4994.

Dampney RA (1994) Functional organization of central pathways regulating the cardiovascular system. Physiol Rev 74:323-364.

DiDomenico R, Nissanov J, Eaton RC (1988) Lateralization and adaptation of a continuously variable behavior following lesions of a reticulospinal command neuron. Brain Res 473:15-28.

Dubuc R, Brocard F, Antri M, Fénelon K, Gariépy JF, Smetana R, Ménard A, Le Ray D, Viana Di Prisco G, Pearlstein E, Sirota MG, Derjean D, St-Pierre M, Zielinski B, Auclair F, Veilleux D (2008) Initiation of locomotion in lampreys. Brain Res Rev 57:172-182.

Eaton RC, Farley RD (1975) Mauthner neuron field potential in newly hatched larvae of the zebra fish. J Neurophysiol 38:502-512.

Eaton RC, Farley RD, Kimmel CB, Schabtach E (1977) Functional development in the Mauthner cell system of embryos and larvae of the zebra fish. J Neurobiol 8:151-172.

Eaton RC, Lavender WA, Wieland CM (1981) Identification of Mauthnerinitiated response patterns in goldfish: evidence from simultaneous cinematography and electrophysiology. J Comp Physiol A Neuroethol Sens Neural Behav Physiol 144:521-531.

Eaton RC, Lavender WA, Wieland CM (1982) Alternative neural pathways initiate fast-start responses following lesions of the Mauthner neuron in goldfish. J Comp Physiol A Neuroethol Sens Neural Behav Physiol 145:485-496.

Eaton RC, Nissanov J, Wieland CM (1984) Differential activation of Mauthner and non-Mauthner startle circuits in the zebrafish: implications for functional substitution. J Comp Physiol A Neuroethol Sens Neural Behav Physiol 155:813-820.

Eaton RC, DiDomenico R, Nissanov J (1988) Flexible body dynamics of the goldfish C-start: implications for reticulospinal command mechanisms. J Neurosci 8:2758-2768.

Faber DS, Korn H (1978) Neurobiology of the Mauthner Cell. New York: Raven.

Fagerstedt P, Orlovsky GN, Deliagina TG, Grillner S, Ullén F (2001) Lateral turns in the Lamprey. II. Activity of reticulospinal neurons during the generation of fictive turns. J Neurophysiol 86:2257-2265.

Fetcho JR (1991) Spinal network of the Mauthner cell. Brain Behav Evol 37:298-316.

Foreman MB, Eaton RC (1993) The direction change concept for reticulospinal control of goldfish escape. J Neurosci 13:4101-4113.

Furshpan EJ, Furukawa T (1962) Intracellular and extracellular responses of the several regions of the Mauthner cell of the goldfish. J Neurophysiol 25:732-771.

Furukawa T, Furshpan EJ (1963) Two inhibitory mechanisms in the Mauthner neurons of goldfish. J Neurophysiol 26:140-176.

Furukawa T, Fukami Y, Asada Y (1964) Effects of strychnine and procaine on collateral inhibition of the Mauthner cell of goldfish. Jpn J Physiol 14:386-399.

Gahtan E, O'Malley DM (2003) Visually guided injection of identified reticulospinal neurons in zebrafish: a survey of spinal arborization patterns. J Comp Neurol 459:186-200.

Gahtan E, Sankrithi N, Campos JB, O’Malley DM (2002) Evidence for a widespread brain stem escape network in larval zebrafish. J Neurophysiol 87:608-614.

Gahtan E, Tanger P, Baier H (2005) Visual prey capture in larval zebrafish is controlled by identified reticulospinal neurons downstream of the tectum. J Neurosci 25:9294-9303.

Gale JE, Marcotti W, Kennedy HJ, Kros CJ, Richardson GP (2001) FM1-43 dye behaves as a permeant blocker of the hair-cell mechanotransducer channel. J Neurosci 21:7013-7025.

Grillner S, Wallén P, Saitoh K, Kozlov A, Robertson B (2008) Neural bases of goal-directed locomotion in vertebrates-an overview. Brain Res Rev $57: 2-12$.

Hackett JT, Faber DS (1983) Mauthner axon networks mediating supraspi- nal components of the startle response in the goldfish. Neuroscience 8:317-331.

Hackett JT, Greenfield LJ (1986) The behavioral role of the Mauthner neuron impulse. Behav Brain Sci 9:729-730.

Harris JA, Cheng AG, Cunningham LL, MacDonald G, Raible DW, Rubel EW (2003) Neomycin-induced hair cell death and rapid regeneration in the lateral line of zebrafish (Danio rerio). J Assoc Res Otolaryngol 4:219-234.

Hatta K, Korn H (1998) Physiological properties of the Mauthner system in the adult zebrafish. J Comp Neurol 395:493-509.

Kimmel CB, Patterson J, Kimmel RO (1974) The development and behavioral characteristics of the startle response in the zebra fish. Dev Psychobiol 7:47-60.

Kimmel CB, Eaton RC, Powell SL (1980) Decreased fast-start performance of zebrafish larvae lacking Mauthner neurons. J Comp Physiol A Neuroethol Sens Neural Behav Physiol 140:343-350.

Kimmel CB, Sessions SK, Kimmel RJ (1981) Morphogenesis and synaptogenesis of the zebrafish Mauthner neuron. J Comp Neurol 198:101-120.

Kimmel CB, Metcalfe WK, Schabtach E (1985) T reticular interneurons: a class of serially repeating cells in the zebrafish hindbrain. J Comp Neurol 233:365-376.

Kimmel CB, Hatta K, Metcalfe WK (1990) Early axonal contacts during development of an identified dendrite in the brain of the zebrafish. Neuron 4:535-545.

Lee RK, Eaton RC (1991) Identifiable reticulospinal neurons of the adult zebrafish, Brachydanio rerio. J Comp Neurol 304:34-52.

Liu KS, Fetcho JR (1999) Laser ablations reveal functional relationships of segmental hindbrain neurons in zebrafish. Neuron 23:325-335.

Metcalfe WK, Mendelson B, Kimmel CB (1986) Segmental homologies among reticulospinal neurons in the hindbrain of the zebrafish larva. J Comp Neurol 251:147-159.

Meyers JR, MacDonald RB, Duggan A, Lenzi D, Standaert DG, Corwin JT, Corey DP (2003) Lighting up the senses: FM1-43 loading of sensory cells through nonselective ion channels. J Neurosci 23:4054-4065.

Murakami SL, Cunningham LL, Werner LA, Bauer E, Pujol R, Raible DW, Rubel EW (2003) Developmental differences in susceptibility to neomycin-induced hair cell death in the lateral line neuromasts of zebrafish (Danio rerio). Hear Res 186:47-56.

Nakayama H, Oda Y (2004) Common sensory inputs and differential excitability of segmentally homologous reticulospinal neurons in the hindbrain. J Neurosci 24:3199-3209.

Neki D, Nakayama H, Fujii T, Oda Y (2007) Functional connection from Mauthner cell to homologous reticulospinal neurons in the goldfish hindbrain. Neurosci Res 58:S92.

Nieuwenhuys R, ten Donkelaar HJ, Nicholson C (1998) The central nervous system of vertebrates. Berlin: Springer.

Nishikawa S, Sasaki F (1996) Internalization of styryl dye FM1-43 in the hair cells of lateral line organs in Xenopus larvae. J Histochem Cytochem 44:733-741.

Nissanov J, Eaton RC, DiDomenico R (1990) The motor output of the Mauthner cell, a reticulospinal command neuron. Brain Res 517:88-98.

Oda Y, Nakayama H (2003) Common synaptic drive from Mauthner cell to segmentally homologous reticulospinal neurons in teleost hindbrain. Soc Neurosci Abstr 29:78.79.

Oda Y, Kawasaki K, Morita M, Korn H, Matsui H (1998) Inhibitory longterm potentiation underlies auditory conditioning of goldfish escape behaviour. Nature 394:182-185.

O’Malley DM, Kao YH, Fetcho JR (1996) Imaging the functional organization of zebrafish hindbrain segments during escape behaviors. Neuron 17:1145-1155.

Orger MB, Kampff AR, Severi KE, Bollmann JH, Engert F (2008) Control of visually guided behavior by distinct populations of spinal projection neurons. Nat Neurosci 11:327-333.

Orlovsky GN, Deliagina TG, Grillner S (1999) Initiation of locomotion. In: Neuronal control of locomotion: from mollusc to man, pp 205-214. New York: Oxford UP.

Owens KN, Cunningham DE, MacDonald G, Rubel EW, Raible DW, Pujol R (2007) Ultrastructural analysis of aminoglycoside-induced hair cell death in the zebrafish lateral line reveals an early mitochondrial response. J Comp Neurol 502:522-543.

Popper AN, Fay RR (1999) The auditory periphery in fishes. In: Comparative hearing: fish and amphibians (Fay RR, Popper AN, eds), pp 43-100. New York: Springer. 
Ritter DA, Bhatt DH, Fetcho JR (2001) In vivo imaging of zebrafish reveals differences in the spinal networks for escape and swimming movements. J Neurosci 21:8956-8965.

Rossignol S, Dubuc R, Gossard JP (2006) Dynamic sensorimotor interactions in locomotion. Physiol Rev 86:89-154.

Saint-Amant L, Drapeau P (1998) Time course of the development of motor behaviors in the zebrafish embryo. J Neurobiol 37:622-632.

Smetters D, Majewska A, Yuste R (1999) Detecting action potentials in neuronal populations with calcium imaging. Methods 18:215-221.

Szabo TM, McCormick CA, Faber DS (2007) Otolith endorgan input to the Mauthner neuron in the goldfish. J Comp Neurol 505:511-525.

Takahashi M, Narushima M, Oda Y (2002) In vivo imaging of functional inhibitory networks on the Mauthner cell of larval zebrafish. J Neurosci 22:3929-3938.

Ullén F, Deliagina TG, Orlovsky GN, Grillner S (1997) Visual pathways for postural control and negative phototaxis in lamprey. J Neurophysiol 78:960-976.

Viana di Prisco G, Alford S (2004) Quantitative investigation of calcium signals for locomotor pattern generation in the lamprey spinal cord. J Neurophysiol 92:1796-1806.

Webb JF, Shirey JE (2003) Postembryonic development of the cranial lateral line canals and neuromasts in zebrafish. Dev Dyn 228:370-385.

Weiss SA, Zottoli SJ, Do SC, Faber DS, Preuss T (2006) Correlation of C-start behaviors with neural activity recorded from the hindbrain in free-swimming goldfish (Carassius auratus). J Exp Biol 209:4788-4801.

Yasargil GM, Diamond J (1968) Startle-response in teleost fish: an elementary circuit for neural discrimination. Nature 220:241-243.

Yeomans JS, Li L, Scott BW, Frankland PW (2002) Tactile, acoustic and vestibular systems sum to elicit the startle reflex. Neurosci Biobehav Rev 26:1-11.

Zottoli SJ (1977) Correlation of the startle reflex and Mauthner cell auditory responses in unrestrained goldfish. J Exp Biol 66:243-254.

Zottoli SJ, Newman BC, Rieff HI, Winters DC (1999) Decrease in occurrence of fast startle responses after selective Mauthner cell ablation in goldfish (Carassius auratus). J Comp Physiol A Neuroethol Sens Neural Behav Physiol 184:207-218. 